\title{
Neue Untersuchungen über den Atemmechanismus mariner Teleosteer.
}

\author{
Von Johannes Henschel, Helgoland. \\ (Aus der Biologischen Anstalt auf Helgoland.)
}

Mit 12 Abbildungen im Text.

\section{Inhaltsverzeichnis :}

Einleitung $\quad \ldots$

I. Der Bauplan des Branchiovisceralapparats . . . . . . . . . . . . . . . . . . . . . . . . . 245

A. Das Skelett. . . . . . . . . . . . . . . . . . . . . . . . . . . . . . 245

B. Die Mundhöhle und die seitlichen Kiemenhöhlen . . . . . . . . . . . . . 248

C. Di e Muskeln . . . . . . . . . . . . . . . . . . . . . . . . . . . . . . . . 248

11. Die Bewegungen und Raumveränderungen des Branchiovisceralapparats bei der Atmung . . . 250

A. Das Schema der Druckpumpe . . . . . . . . . . . . . . . . . . . . . . . . . . 250

B. Das Schema der Saugpumpe . . . . . . . . . . . . . . . . . . . . . . . . 253

III. Die Versuche über den Mechanismus und die Physiologie des Atemapparats . . . . . . . . 256

A. Versuehe mit Schollen . . . . . . . . . . . . . . . . . . . . . . . . . 257

1. Beobachtungen der Atemfrequenz uud des Berregungsmodus . . . . . . . . . . . 257

2. Direkter Nachweis der Saugleistung der seitlichen Kiemenhöhlen . . . . . . . . . . . 260

3. Quantitative Leistung jedes Atemzugs . . . . . . . . . . . . . . . . . . . 262

4. Die Bedeutung verschiedener Branchiovisceralmuskeln für den Atmungsakt . . . . . . 264

a) Anatomie der Atmungsmuskeln . . . . . . . . . . . . . . . . . . . . . . . 265

b) Saugleistung nach Durchschneidung verschiedener Muskeln . . . . . . . . . . . 268

B. Versuche mit Dorschen . . . . . . . . . . . . . . . . . . . . . . . . 272

IV. Vergleich der Atemapparate von Dorsch und Scholle . . . . . . . . . . . . . . . . . 274

Zusammenfassung . . . . . . . . . . . . . . . . . . . . . . . . . . . . . . . . 276

Schriftenverzeichnis . . . . . . . . . . . . . . . . . . . . . . . . . . . . . . . . 278

\section{Einleitung.}

Schon in früheren Jahren, bereits um die Jahrhundertwende und in dem Jahrzehnt darauf, wurde über den Atemmechanismus der Knochenfische gearbeitet, und das Bild, das man sich von der Wirkung der Atembewegungen machte, hatte durch das Atemschema von BAGLION (1906) einen gewissen Abschluß bekommen. Wenn dies Problem in letzter Zeit trotzdem wieder in den Vordergrund der Forschung gerückt ist, so muß hierfür besonders eine Entdeckung WoskobolnikofF's (1932) verantwortlich gemacht werden, die die alten Anschauungen über den Atmungsakt der Knochenfische wieder in Frage gestellt hat. Es hat sich zwar erwiesen, daß BAGLIon's Schema, so falsch, wie es zunächst schien, nicht gewesen ist. Trotzdem bedürfen die alten Anschauungen einer gewissen Verbesserung. Sie sind zu schematisch gewesen, sie haben die Kompliziertheit des Atmungsapparates $\mathrm{zu}$ wenig in Rechnung gestellt.

Es drängt sich ja, wenn man die Organisation der Knochenfische, besonders das Skelett betrachtet, von selbst der Gedanke auf, daß hier überall Differenzierung, die über das Schema ursprünglicher Einfachheit 
hinausgeht, stattgefunden hat durch Vermehrung der einzelnen Glieder und daher unter Komplizierung des Ganzen. Man vergleiche z. B. das Kopfskelett oder etwa den Schultergürtel eines Teleosteers mit dem eines Selachiers. Welch eine starke Vermehrung der einzelnen Glieder bei dem Knochenfisch. Wenn man sich aber die Teleosteerknochen als einzelne betrachtet, so bemerkt man, daß sie die ursprüngliche Form eines Knochenblatts oder einer Knochenspange fast immer bewahrt haben. Von einer Verschmelzung mehrerer Knochen, einer Formumbildung oder gar der starken Herausarbeitung und Differenzierung eines einzelnen Knochens bei Rückbildung der übrigen, wie dies für die Entwicklungsreihe höherer Wirbeltiere so charakteristisch ist, ist noch wenig zu bemerken. Die Differenzierung der Teleosteer hat auf einer recht niedrigen Entwicklungsstufe stattgefunden.

Ein so besonders kompliziert gebautes Organ ist nun gerade das Branchiovisceralskelett, das zudem zwei Funktionen gleichzeitig zu leisten hat, nämlich den Transport des Atemwassers durch die Mundkiemenhöhle und das Ergreifen und Verschlingen der Beute. Man wird daher auch einen Funktionsmechanismus zu erwarten haben, der sich nicht mit einem einfachen Schema wiedergeben läßt.

Es wird in Folgendem der Bauplan des Branchiovisceralskeletts besprochen und die Atmungsfunktion an Hand eigener Versuche entwickelt werden. Als Versuchstiere dienten mir der Dorsch, ein Fisch mit einem typischen, Scholle und Flunder, zwei Bodenfischarten mit spezialisierten Atmungsapparaten.

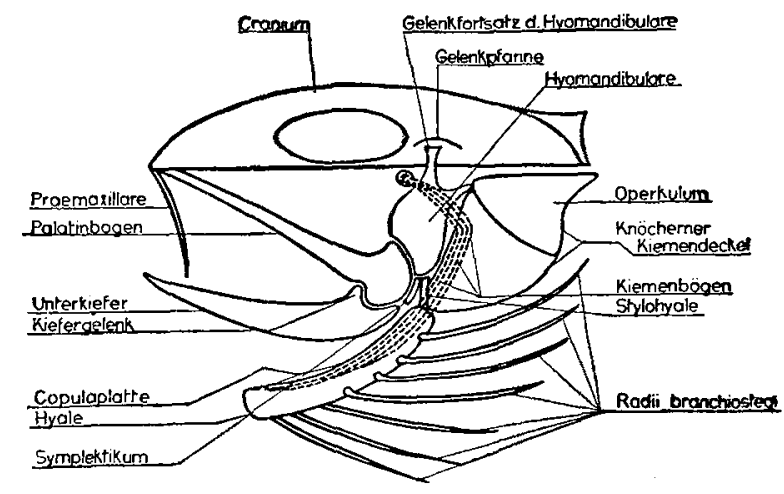

Abb. 1. Schema eines Gadusschädels. (Aus: Henschel (1939), der Atmungsmechanismus der Teleosteer.)

\section{Der Bauplan des Branchiovisceralapparats.}

Um die Funktion eines Organes zu verstehen, muß man seinen Bauplan kennen. Dieser wird am deutlichsten an den Formen sichtbar werden, die nach keiner Seite hin größere Differenzierungen erfahren haben. Dies gilt für den Gadusschädel. Der Kabeljau z. B. führt, wie alle Gadiden eine Lebensweise, die man für Knochenfische als typisch bezeichnen kann. Er ist kein Standfisch, er wechselt häufig seinen Ort, führt auch größere Wanderungen aus, kann also leicht in frisches, sauerstoffreiches Wasser gelangen. Ebensowenig gehört er aber zu den ständig vorwärtseilenden Dauerschwimmern, sondern hält sich gelegentlich auch längere Zeit an ein- und derselben Stelle auf. So findet man bei ihm den Atemapparat in recht ursprünglicher Form und alle Glieder desselben gleichmäßig und normal entwickelt. Aus diesem Grunde habe ich den. Kabeljauschädel als typisches Beispiel für den Bauplan eines Branchiovisceralapparates gewählt.

\section{A. Das Skelett.}

Das Gerüst des Kiemenapparats wird vom Visceralskelett gebildet. Dies besteht aus sieben Paar Knochenbögen: dem Kiefer-, dem Zungenbeinbogen und den fünf Kiemenbögen. Sechs dieser sieben Bogenpaare haben einen recht gleichmäßigen, sehr charakteristischen Verlauf (Abb. 1 und 2). Sie beginnen in der hinteren Region der Schädelkapsel jederseits des Kopfes. Sie senken sich in je einem kürzeren, dorsalen Knochenstück nach hinten und etwas nach außen. Ihre ventralen, längeren Stücke, mehr oder weniger scharf gegen die dorsalen Teile eingewinkelt, senken sich dagegen nach vorn und innen und treffen sich in der ventralen Mittellinie des Mundbodens nahe der Mundöffnung. Die beiden Bogenhälften haben demnach ihre größte Entfernung voneinander in der Knick- 
stelle der dorsalen und ventralen Schenkel. Durch diesen Verlauf bekommt die Mundhöhle des Fisches ihre charakteristische, seitliche Auswölbung und das Kiemenskelett die Form eines Kiemenkorbes. Einer der Bögen und zwar der 1., der Kieferbogen, folgt nicht diesem Verlauf. Er hat durch die Anpassung an die Funktion des Kiefergelenks Veränderungen erfahren. Das dorsale Stück jedes Einzelbogens besteht aus einer Knochenplatte (aus Quadratum und Metapterygoid gebildet), die in die Backenregion jeder Kopfseite ventral verlagert und nicht mit dem Schädel verbunden oder im Bindegewebe der Schädelbasis verankert ist. Die beiden Knochenplatten laufen nach vorn in zwei Knochenstreben aus (Ekto- und Entopterygoid), verbinden sich mit den Gaumenbeinen (Palat in um) jeder Seite zu je einer gemeinsamen Knochenspange und befestigen sich dort an der Nasenregion des Schädels. Die ventralen Stücke bilden die Unterkieferspange, also die ventrale Umrandung der Mundöffnung. Der Unterkiefer (Dentale und Angulare) ist mit der Knochenplatte des Quadratum und Metapterygoid gelenkig verbunden durch die beiden Gelenkknochen des primären Kiefergelenks, das Quadratum und Articulare. Die dorsale Umrandung der Mundöffnung wird bekanntlich vom Prämaxillare gebildet, das die Funktion des Oberkiefers übernommen hat. Das Maxillare bildet nur eine von der Nasenregion frei herabhängende Knochenspange zur Versteifung der häutigen Backenwand der Mundhöhle. Prämaxillare und De ntale sind nicht gelenkig, sondern nur durch ein dehnbares Ligament miteinander verbunden: Eine Anpassung an das Verschlingen großer Beutestücke. Präm axillare und Maxillar e werden bei geschlossenem Maul zurückgeschlagen und dem Unterkiefer angelegt.

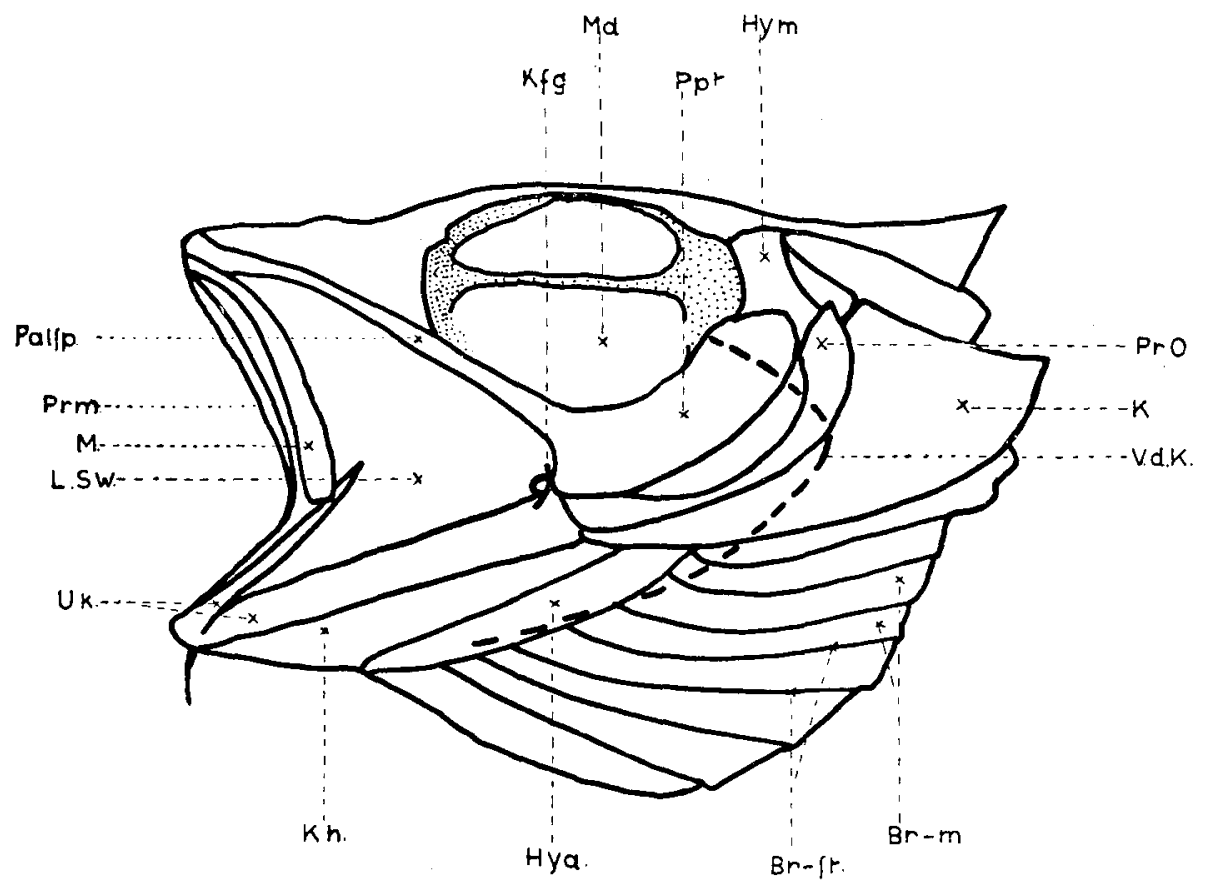

Abb. 2. Getrockneter Dorschschädel, etwas schematisch. (Augen und Backenmuskulatur abpräpariert.) Zeichenerklärung: Kfg. = Kiefergelenk, Md. = Munddach, Ppt. == Palatopterygoidplatte, Hym.= Hyomandibulare, Pro. $=$ Praeoperculum, K. = Kiemendeckel. V. d. K. = Verlauf der innen gelegenen Kiemenbögen schematisch, Br-m. = Branchiostegalmembran, Br-st. = Branchiostegalstrahlen, Hya = Hyale, Kh. = Kehlhaut, UK. = Unterkiefer, L. SW. = Linke Seitenwand der Mundhöhle (häutig), M. = Maxillare, Prm. = Praemaxillare, Palsp. = Palatinspange.

Der zweite Bogen, der Hyoid- oder Zungenbeinbogen hat den typischen, eben besprochenen Verlauf dieser Bögen. Sein dorsales Stück, das Hyomandibulare, ist mit der Schädelkapsel durch einen Gelenkfortsatz verbunden, der in einer Art Gelenkpfanne, vom Squamosum und Postfrontale gebildet, ruht. Dieser Knochen zeigt die Form einer unregelmäßigen Knochenplatte. Er besitzt Vorsprünge und Leisten zum Ansatz von Muskeln. An seiner vorderen Kante ist er mit der Pterygoidplatte zu einer festen Knochenplatte verwachsen. Ein weiteres, ihm ventral anhängendes Knochen- 
stäbchen, das Symplecticum, verwächst mit dem Quadratum. Das Hyomandibula re besitzt an seinem dorsalen, hinteren Rande noch einen zweiten Gelenkfortsatz, an dem der Hauptknochen des Kiemendeckels, das Operculum gelenkig befestigt ist. Durch die enge Verwachsung der Pterygoidplatte mit dem Hyomandibulare wird letzteres zum Verbindungsglied des Kieferbogens mit dem Cranium. Diese Anordnung der Knochen, die bekannte Hyostylie, hat dem Fischschädel seine charakteristische Architektur gegeben. Es wird später gezeigt werden, daß sie zum Teil auch aus der Funktion der Atmungsbewegungen biologisch verständlich wird. Die ventralen Teile jeder Kopfseite bilden die Hyalia oder Zungenbeine. Sie senken sich entsprechend dem geschilderten Bogenverlauf an beiden Backenseiten schräg nach vorn und innen und sind in der vorderen Mundregion innerhalb der Unterkieferspange durch einen kleinen Knochen (Copula) miteinander verbunden. Sie tragen in ihrer Verbindungsstelle den Stützknochen der Zunge, das Entoglossum. Die ganze Verbindungsstelle wird also zum Stützgerüst für den Zungenhügel, der sich über der Knochenbrücke der Zungenbeine erhebt, wonach der Bogen auch seinen Namen erhalten hat. Die Zungenbeine selbst stellen breite Knochenleisten dar, die aus drei Gliedern bestehen: Einer oberen Hälfte, dem Epihyale, einer unteren Hälfte dem Ceratohyale und einem kleinen Endglied Hypohyale, das mit der Copula in Verbindung steht. Diese Unterteilung in Glieder ermöglicht der Zungenbeinleiste eine leichte, seitliche, nach außen gerichtete Einknickung. Die Hyalia sind mit den beiden Hyomandibularia nicht direkt, sondern durch einen kleinen Knochenstiel, das Stylohyale verbunden.

Im Gegensatz zu den ersten beiden Bögen, die die Außenwände der Mundhöhle bilden oder ihnen ihre Stützen liefern, sind die fünf folgenden Bögen, die Kiemenbögen, ins Innere der Mundhöhle verlagert. In der Aufeinanderfolge liegt jeder hintere Bogen gegen den vorderen auch etwas nach innen gerückt. Dadurch erhält der Kiemenkorb zu der besprochenen Wölbung in dorsoventraler Richtung noch eine Wölbung in der Horizontalen, die kaudal nach außen gerichtet ist, wodurch die korbförmige Gestalt der Kiemenbögen noch stärker herausgearbeitet erscheint. Nur die ersten vier Bögen sind voll entwickelt. Ihre dorsalen Stücke, die Epibranchialia, sind jederseits der hinteren Schädelregion im Bindegewebe der Schädelbasis verankert (von der Mundhöhle aus gesehen im Mundhöhlendach). Sie stehen durch eine Knochenplatte, zu der die vier Pharyngobranchialia, die obersten Glieder verschmolzen sind, miteinander in Verbindung. Jeder dieser beiden Knochenplatten, die im Mundhöhlendach jederseits des Schlundes hängen, hat eine Zahnplatte mit nach hinten gerichteten Zähnen ausgebildet, die die Funktion hat, halb verschlungene Beutestücke vor dem Zurückgleiten aus dem Schlund in die Mundhöhle zu verhindern. Die ventralen Stücke der Kiemenbögen sind stark gegen die dorsalen eingewinkelt. Sie senken sich schräg nach vorn und innen und laufen hinter dem Zungenhügel zwischen den Zungenbeinen, ein Bogenpaar hinter dem anderen, zusammen. Die Stücke jedes Paares sind wie die Zungenbeine durch Copulae miteinander verbunden. Die Copula e der einzelnen Bögen sind wieder untereinander und mit der Copula des Zungenbeinbogens durch Knorpelstücke verbunden, sodaß die Verbindungsstücke des zweiten bis siebenten Bogens die einheitliche Knochenplatte des Mundbodens bilden.

Auch die ventralen Stücke der Kiemenbögen sind in Glieder unterteilt. Sie bestehen aus den Ceratobranchialia und Hypobranchialia, die mit den Copulae in Verbindung stehen. Da sich die Mundhöhle nach hinten verjüngt, müssen die ventralen Stücke immer kürzer werden. Sie verkürzen sich auf Kosten der Hypobranchialia. Im ersten Kiemenbogenpaar nehmen diese Knochen noch annähernd die Hälfte des ventralen Stückes ein. Im dritten Paar bilden sie nur noch kleine, kurze Knochenstücke neben der Copula, im vierten Bogen fehlen sie ganz. Dort sind die Ceratobranchialia mit der Copula in direkter Verbindung. Auch die Kiemenbögen können sich durch ihre Unterteilung in Glieder leicht einknicken.

Der fünfte Bogen ist rückgebildet. Es sind von ihm nur kurze ventrale Knochenstäbe erhalten geblieben, die in die Schlundhaut des Mundbodens jederseits des Schlundes eingelagert sind. An ihrer der Mundhöhle zugekehrten Seite tragen sie Zahnplatten mit nach hinten gerichteten Zähnen, die ebenso wie die beiden Zahnplatten des Munddachs Beutestücke am Zurückgleiten hindern sollen.

Während die fünf Kiemenbögen ins Innere der Mundhöhle gerückt sind, übernahm ein anderes Organ die Funktion, den Mundkiemenhohlraum abzuschließen und zugleich den Kiemenapparat zu schïtzen: Der Kiemendeckel, der die Wand des hinteren Teiles dieses Hohlraumes bildet. Er schließt sich eng an den Hyoidbogen an. Er besteht, wie 
die Bögen des Visceralskeletts, aus einem dorsalen Teil, der dem Hyomandibulare, und einem ventralen Teil, der dem Hyale zugeordnet ist.

Der dorsale Teil, der knöcherne Kiemendeckel, besteht aus vier Knochenplatten. Sein Hauptknochen, das Operculum, ist eine annähernd dreieckige Platte, die mit dem hinteren Stiel des Hyomandibulare gelenkig verbunden ist. Seine obere Kante ist mit der hinteren Schädelregion häutig verwachsen. Nach hinten lagert sich ihm das Suboperculum, ventral das Interoperculum an, beides schmale Knochenplatten. Das Präoperculum nimmt eine Sonderstellung ein. Es liegt vor den drei erwähnten Opercularknochen, überdeckt sie mit seinem hinteren Rande, ist dagegen befestigt am Hyomandibulare und sogar am Quadratum, zu welchem Knochen es auch in funktionelle Beziehung getreten ist.

Den ventralen Teil des Kiemendeckels bildet die Kiemendeckelhaut oder Branchiostegalmembran. Diese häutige Wandung wird durch sieben elastische Knochenstäbe versteift, die radii branchiostegi oder Branchiostegalstrahlen, die am Hyale befestigt sind und in der Membran frei enden. In ihrer nach oben und leicht nach außen gebogenen Form schmiegen sie sich der Rumpfform des Fisches, dort, wo sie aus der Seitenfläche in die Bauchfläche übergeht, eng an. Der äußere Rand dieser Membran folgt in seinem Verlauf der Richtung des Hyale, er flieht von den Seiten schräg unter die Bauchfläche nach vorn. In der ventralen Mittellinie sind die Membranen beider Seiten miteinander verwachsen.

Der hintere freie Rand des knöchernen Kiemendeckels und der Branchiostegalmembran liegt den Knochen des Schultergürtels (Cleithra) auf. Diese beiden Knochenbögen, jederseits der Halswirbel entspringend, umspannen die Körperhöhle und verlaufen von den Seitenflächen des Rumpfs schräg nach unten und vorn, bis sie sich unter der Schlundregion hinter der Copulaplatte der Kiemenbögen in der ventralen Mittellinie treffen.

\section{B. Die Mundhöhle und die seitlichen Kiemenhöhlen.}

Nach Schilderung der verschiedenen Teile des Visceralskeletts und der ihm benachbarten Skelettglieder wird es zweckmäBig sein, die Hohlräume zu beschreiben, die von diesen Knochen umgeben werden (s. Abb. 2). Den vorderen Teil dieser Hohlräume nimmt die Mundhöhle ein. Sie wird oben begrenzt vom Mundhöhlendach, einer Haut, die sich zwischen die Palatinspangen beider Seiten und der Schädelbasis (Ethmoidalregion, Parasphenoid und Vomer) ausspannt. Ihre seitlichen Wände bilden die Knochen der Kiefer- und Zungenbeinbögen und die zwischen ihnen ausgespannten Häute. Den Mundboden bildet die Kehlhaut zwischen der Unterkieferspange, weiter der freibewegliche Zungenhügel mit seinem Stützskelett und die mit ihm verbundene Copulaplatte der Kiemenbögen. In der Schlundregion beteiligt sich an der Bildung der Mittelpartie des Mundbodens die dorsale Wand der sich nach vorn auskeilenden Körperhöhle, die von den Knochen des Schultergürtels umfaßt wird. Seine seitlichen Partien werden von den ventralen Stücken der Kiemenbögen gebildet. Die vom Schlund durchbohrte Schlundwand und die zu ihren beiden Seiten zum Mundhöhlendach aufsteigenden Rippen der Kiemenbögen schließen die Mundhöhle nach hinten ab. Die Kiemenbögen haben zwischen sich Spalten ausgespart, die in zwei neue Hohlräume führen, die seitlichen Kiemenhöhlen. Diese liegen neben dem unter die Schlundregion sich auskeilenden vorderen Teil der Leibeshöhle, die den Oesophagus und ventral das Herz enthält. Ihre vordere Begrenzung finden sie in den beiden bogenförmig verlaufenden Kiemenbogengruppen. Dorsal werden sie durch die Verwachsungsnaht des Operculum mit der Occipitalregion des Schädels geschlossen. Als äußere Seitenwände fungieren, wie schon erwähnt, Kiemendeckel und Branchiostegalmembran. Nach hinten öffnen sie sich zwischen Kiemendeckel und Schultergürtel durch den Kiemenspalt nach außen. Sie liegen demnach seitlich hinter und im ventralen Bezirk unter der Mundhöhle. Zugleich gehen die Höhlen beider Seiten in der ventralen Mittellinie ineinander über.

\section{Die Muskeln. ${ }^{1}$ )}

Die einzelnen Skelettelemente und Partien der Mund- und Kiemenhöhle werden von sehr verschiedenen Muskelgruppen bedient. Thre Zahl und Vielgestaltigkeit spiegelt die Kompliziertheit des ganzen Apparats wieder. Während die Skeletteile der einzelnen

1) Muskelbeschreibung im Anschluß an BABAK 1931 und VETTER 1878. 
Bögen ihrer Anordnung gemäß nacheinander betrachtet wurden, werden die verschiedenen Muskelsysteme besser in eine dorsale und eine ventrale Muskelgruppe $\mathrm{zu}$ trennen sein, je nachdem sie die dorsalen oder ventralen Glieder der Bögen bedienen. Führen doch die ventralen Bogenteile im großen und ganzen Bewegungen in dorsoventraler Richtung aus. Während die dorsalen Glieder die seitliche Abhebung und Anziehung der Backenregion und der Kiemendeckelpartie bewerkstelligen. Im einzelnen sind die Bewegungen aber so ineinander verflochten, daß es bei der Besprechung ihrer Funktion oft schwer sein wird, die Tätigkeit dieser beiden Gruppen streng voneinander $\mathrm{zu}$ trennen.

Der stärkste Muskel in der Kehlpartie ist der Musculus sternohyoideus, der die in der Kehlhaut freibewegliche Zungenspange und mit ihr die Copulaplatte der Kiemenbögen nach unten und hinten zieht. Er heftet sich am Innern des Zungenbeinbogens an und führt unter der Copulaplatte zu den Seitenflächen der Cleithra, wo er nahe ihrer ventralen Verwachsungslinie inseriert. Bei stärkerer Kontraktion wird der Unterkiefer, der ja durch die Kehlhaut mit dem Zungenbeinbogen verbunden ist, in die Abwärtsbewegung mit einbezogen. Das leichte Aufklappen des Unterkiefers sollen aber (nach BABÁK 1931) bestimmte Fasern eines anderen Muskelpaares, des Musculus geniohyoideus, bewirkenn. Dieses Muskelpaar, jederseits am Unterkiefer anheftend, überkreuzt sich in der Kehlhaut mit einigen Fasern und inseriert an den beiden Außenseiten des Ceratohyale etwa im Bereich des dritten Branchiostegalstrahls. Als sein und des Sternohyoideus Antagonist fungiert der Museulus adductor mandibularis, der die Muskelmasse der Backenpartie bildet, also zwar teilweise auf der dorsalen Gesichtshälfte liegt, aber doch vorwiegend ventrale Glieder bedient. Er entspringt am Innenrande des Metapterygoid, des Hyomandibulare und des Präoperculum, das ja zu den ersten beiden Knochen in nähere Beziehung getreten ist. Dieser Muskel entsendet auch einige Fasern zum Oberkiefer, den er herabzieht, seine Hauptmasse bedient aber den Unterkiefer, den er - und gleichzeitig den Zungenbeinbogen - nach oben zieht. Er ist der Schließmuskel der Mundöffnung. Am Heraufziehen des Zungenbeinbogens beteiligen sich aber auch Fasern des Geniohyoideus. Wenn der Adductor mandibularis den Unterkiefer fixiert hält, kann auch der Geniohyoideus allein als Antagonist des Sternohyoideus bei der Zungenbewegung fungieren (HoLMQUisT 1910).

Die seitliche Abhebung, eine Bewegung der dorsalen Bogenteile, fällt den dorsalgelegenen Muskelgruppen zu. Als erster, wichtigster ist der Musculus levator arcus palatini zu nennen. Er stellt eine pyramidenförmige Muskelmasse dar, die ame Postorbitalfortsatz der Schädelkapsel entspringt, sich nach vorn erweitert und am Innrnrand der Palatopterygoidplatte und auch am Hyomandibulare inseriert. Er liegt untes dem Musculus Adductor mandibularis. Sein Antagonist, der Adductor arcus palatini, ent pringt an der Schädelbasis, am Parasphenoid und inseriert an der Innenfläche des Palatinbogens. Er verläuft also über dem Dach der Mundhöhle. Er wird dabei in seiner Wirkung unterstützt vom Musculus adductor hyomandibularis, der von der Schädelwand zur Innenfläche des Hyomandibulare verläuft.

Der Kiemendeckel hat eine eigene Muskulatur, die auch der Gruppe der dorsalen Muskulatur zugerechnet werden muß. An der Abhebung der Kiemendeckel beteiligen sich je zwei Muskeln: Der Musculus levator operculi, vom hinteren Ende des Squamosum zum hinteren Rand des Operculum ziehend; er hebt das Operculum, seine hinteren Fasern drücken aber den Außenrand dieses Knochens gegen den Schultergürtel. Vor ihm liegt der Musculus dilatator operculi, der den Kiemendeckel noch weiter abhebt und seinen Außenrand vom Schultergürtel löst. Der Antagonist zu diesen Muskeln, der die Kiemendeckel adduciert, ist der Mu s cu I u s adductor operculi, der von der Occipitalregion des Schädels nach der Innenseite des Operculum zieht.

Die Muskeln der Kiemenbögen sind nicht sehr stark entwickelt. Es sind kleine Muskelbündel, die die Bewegungen der Kiemenbögen, die ihnen ja schon durch ihre Verwachsung mit dem Zungenbeinbogen über die Copulaplatte vorgeschrieben sind, unterstützen und modifizieren. Die Musculi levatores arcuum branch. externi und interni führen vom Squamosum zu den Epibranchialia und heben die Kiemenbögen, wobei sie sie ein wenig spreizen. Die Musculi interarcuales dorsales, zwischen Glied und Glied bzw. zwischen Glied des einen und des benachbarten Bogens ausgespannnt, heben diese Bewegungen im dorsalen, die $\mathrm{Musculi}$ interarcuales ventrales heben sie im ventralen Kiemensystem wieder auf.

Die Muskeln der Branchiostegalmembran und der Kiemenhautstrahlen werden im physiologischen Teil besprochen werden. 
Innerviert werden die Muskeln des Visceralskeletts, um auch dies noch zu erwähnen, vom V. und VII. Gehirnnerven (Kiefer- und Zungenbeinbogen, Operculum); die Muskeln der Kiemenbögen werden vom IX. und X. Nerven bedient. Der Musculus sternohyoideus wird dagegen von den ersten beiden Rückenmarksnerven versorgt.

\section{Die Bewegungen und Raumveränderungen des Branchiovisceralapparates bei d er Atmung.}

Am Anfang dieser Arbeit wurde erwähnt, daß dem Branchiovisceralapparat zwei Funktionen zufallen, die Nahrungsaufnahme und die Erneuerung des Atemwassers. Es ist nicht zu verkennen, daß beide einander ähnlich sind. In beiden Fällen findet eine Aufnahme ron Stoffen statt, die für den Stoffwechsel des Organismus notwendig sind. Die Ausbildung des Kiemendarms bei Amphioxus ist daher sinngemäß. Der Darm ist hier noch ganz allgemein Stoffaufnahmeorgan. Die Zone der Sauerstoffaufnahme liegt vor der Zone der Nahrungsaufnahme, nur räumlich, nicht organisch von ihr getrennt. Das verbrauchte Wasser wird nicht als Ballast bis zum After transportiert, sondern durch das Spaltensystem des Kiemendarmes aus dem vorderen Darmabschnitt entlassen. Dadurch wird eine schnelle Wassererneuerung ermöglicht. Weiter wird bereits hier eine Vergrößerung der respiratorischen Oberfläche angebahnt. Zugleich bildet der Kiemendarm einen Filterapparat, der die Nahrung des Lanzettfischchens vor den Kiemenspalten zurückhält und sie weiter in den Darm leitet. Auch diese Funktion hat sich im bekannten Reusenapparat der Kiemenbögen bis zu den hochentwickelten Knochenfischen erhalten.

Im Branchiovisceralapparat, der ja nichts anderes als ein umgebildeter Kiemendarm ist, tritt uns nun dasselbe Funktionsprinzip wie im Kiemendarm entgegen: Er dient gleichzeitig der Atmung und der Nahrungsaufnahme. Dieselben Muskeln, oft sogar dieselben Skeletteile, die die Pumpbewegungen zur Durchleitung frischen Wassers ausführen, bewerkstelligen durch etwas stärkere Kontraktion bzw. eine andere Stellung das Erfassen, Festhalten und Verschlingen der Beute. Man wird, um die Atmungsbewegungen zu verstehen, nicht vergessen dürfen, daß derselbe Apparat zur Nahrungsaufnahme dient, und oft einen Seitenblick auf diese Funktion werfen müssen. In der Arbeit der seitlichen Kiemenhöhlen allerdings hat sich eine Verselbständigung der Atembewegungen eingeleitet, die bei einigen Formen zur vollständigen Tremnung geführt hat. Im allgemeinen gehen die Bewegungen beider Funktionen aber ineinander über.

\section{A. Das Schema der Druckpumpe.}

In richtiger Beurteilung der Doppelfunktion des Mundkiemenapparats haben die ersten Forscher daher die Atmungsbewegung als eine Art Schluckbewegung aufgefaßt (nach BАвік 1931). Der Fisch sollte darnach Wasser schnappen, etwa wie er ein Beutestück schnappt. Durch wellenförmiges Zusammenpressen erst der Mundhöhle, dann des Kiemendeckels würde eine Art peristaltischer Bewegung hervorgerufen, die das Wasser nach hinten leitet. Deutlich tritt in dieser Anschauung die Parallele zur Nahrungswanderung hervor. Bald bemerkte man jedoch, daß die Durchleitung des Atemwassers auf einem anderen mechanischen Prinzip beruhen mußte. Aus der Schlucktheorie entwickelte sich das Schema der Druckpumpe. Dieses, am klarsten von BAGLIon (1907) zur Darstellung gebracht, galt lange Zeit als die befriedigendste Erklärung der Atembewegung.

BAglonis's Schema (Abb. 3) läßt die Mundhöhle und die seitlichen Kiemenhöhlen als einen einheitlichen Hohlraum erscheinen. In der Inspirationsphase wird dieser Raum stark erweitert. Während der häutige Rand des Kiemendeckels und der Kiemendeckelmembran durch den Außendruck des Wassers fest an die Fläche des Schultergürtels gepreßt wird und den Kiemenspalt verschließt, wird durch das geöffnete Maul Wasser in den Hohlraum gesaugt, bis. der Unterdruck ausgeglichen und die Mundhöhle gefüllt ist. Nun tritt die Exspiration ein. Das Maul wird geschlossen, die Mundhöhle verengt sich, das Wasser wird durch die seitlichen Kiemenhöhlen und die Kiemenspalten nach hinten ausgestoßen, wobei sich die weiche Membran von dem Schultergürtel abhebt. Der Mundverschluß in der Exspirationsphase ist oft nicht vollständig. Dafür besitzt eine Reihe von Fischen in den Mundklappen ein Rückschlagventil, das dem zurückdrängenden Wasser den Rückweg durch die Mundöffnung versperrt.

Die Mundklappen sind zwei zwischen die Spange des Ober- bzw. des Unterkiefers ausgespannte Hautfalten, die frei in die Mundhöhle ragen. In der Inspirationsphase werden sie durch den Sog des ein- 
dringenden Wassers nach hinten in die Mundhöhle geklappt und öffnen den Mundspalt. In der Exspiration werden sie durch das zuriickdrängende Wasser vorgeklappt und verschließen ihn.

In dieser Auspressung des Wassers nach hinten sah BAGLIonI die Hauptarbeitsleistung der Mundkiemenhöhle, indem er glaubte, daß hauptsächlich in dieser Phase das Atemwasser an den Kiemen vorbeigeführt und Sauerstoff aufgenommen wird. Dies ist, wie gezeigt wird, nicht richtig. Im einzelnen hatte er aber den Bewegungsmechanismus verschiedener Glieder richtig erkannt, welcher daher an dieser Stelle kurz geschildert werden möge.

Die Mundhöhle erweitert sich in der Inspiration nach zwei Richtungen hin, einmal in ventraler, zweitens in lateraler Richtung. Die ventrale Erweiterung kommt durch Bewegungen der ventralen Bogenteile zustande. Als Beweger sollen dabei die Muskeln dieser Knochenglieder fungieren, die Unterkiefer und Zungenbeine nach abwärts ziehen. Bei normaler Atmung sind die Unterkieferbewegungen geringer als die Bewegungen der Zungenbeine. Dies wäre nach der im ersten Kapitel besprochenen Muskeltätigkeit durch Fixierung des Unterkiefers vom Adductor mandibularis und das Spiel des Sternohyoideus und seines Antagonisten, des Geniohyoideus, möglich. Da der Zungenbeinbogen in der Kehlhaut frei beweglich ist, wölbt er beim Herabgezogenwerden die Kehlhaut nach unten

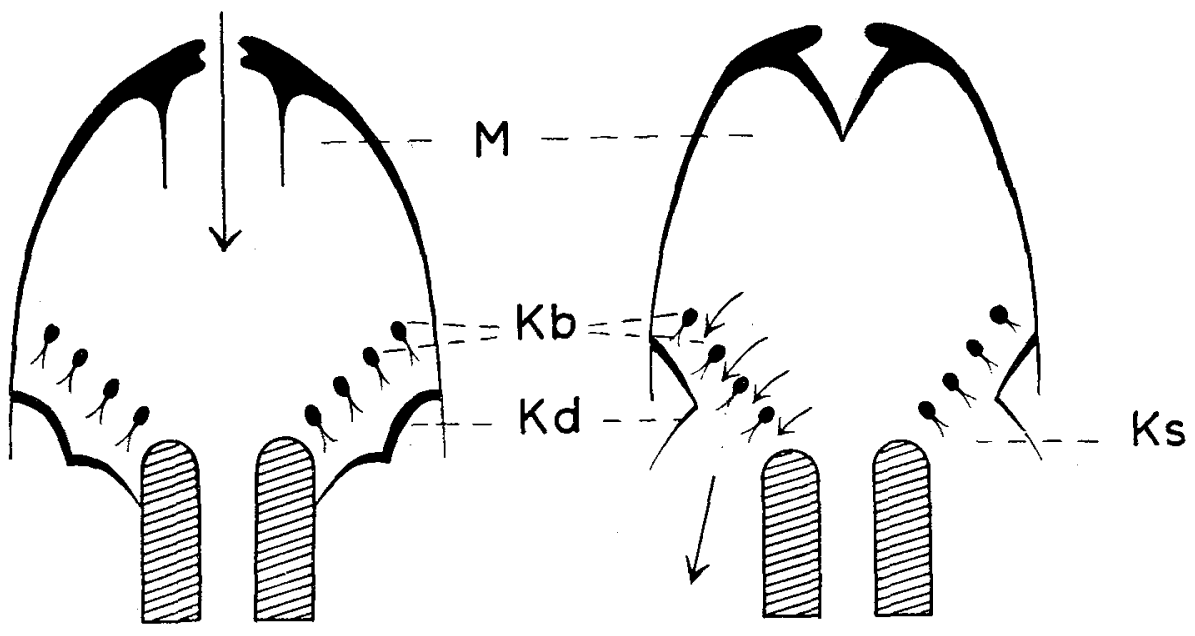

A

B

Abb. 3. Atemmechanismus der Teleosteer. Baglionl's Schema der Druckpumpe (Aus Baglioni 1910). A. Inspiration

B. Exspiration

Zeichenerklärung: $\mathrm{M}=$ Mundhöhle, $\mathrm{Kb}=$ Kiemenbögen, $\mathrm{Ks}=\mathrm{Kiemenspalt,} \mathrm{Kd=Kiemen-}$ deckelapparat. Die Pfeile geben die Richtung des ein-bzw. austretenden Wassers an.

und erweitert die Mundhöhle in ventraler Richtung, ohne den Mundspalt zu vergrößern. Offenbar hat das Tier einen Vorteil davon, die Mundhöhle zu erweitern, möglichst ohne den Oeffnungsdurchmesser des Mauls zu vergrößern, weil dadurch die Saugkraft auf das einströmende Wasser gestejgert wird. Vielleicht ist dies einer der Gründe, warum bei vielen Fischen die aktive Unterkieferbewegung fast ganz durch das Spiel der Mundklappen ersetzt wird.

Bei Fischen, die im Sande vergraben leben, mag die Stillhaltung des Unterkiefers noch eine andere biologische Bedeutung haben. Die Kieferbewegung würde den Sand aufwirbeln, sodaß der Fisch dauernd Sandpartikel mit dem Atemstrom einsaugen müßte. Dies wird durch die Fixierung des Unterkiefers vermieden.

Viel stärker vergrößert die seitliche Abhebung der Backenpartien den Hohlraum, ohne den Durchmesser der Mundöffnung zu verändern. Dies Abspreizen der Backenknochen wird schon durch die Bewegungen der Zungenbeine passiv hervorgerufen. Bereits die Stellung der Visceralbögen mit ihren leicht nach außen gestellten dorsalen Gliedern muß eine Spreizung der Bögen nach außen und damit eine Abhebung der Backenpartie begünstigen. Wird das Zungenbein durch den Sternohyoideus nach hinten 
gezogen, drückt sein dorsales Ende, das ja in der losen Verbindung mit dem Hyomandibulare keinen festen Drehpunkt besitzt, nach oben. Aber durch die Verbindung mit dem Hyomandibulare, dessen eigener Drehpunkt dorsal in der Gelenkpfanne der Schädelkapsel liegt, wird es zugleich verhindert, nach oben auszuweichen. Es folgt der schon durch seinen Bauplan vorgezeichneten Bewegungsrichtung, nämlich es spreizt sich nach außen ab. Der Grad dieser Abduktion wird noch dadurch vergrößert, daß das Hyale mit dem Hyomandibulare nicht direkt, sondern über den kleinen Zwischenknochen, das Stylohyale verbunden ist. Dieser Knochen hebt aber, wenn er vom Hyale zur Seite gezogen wird, gleichzeitig das Hyomandibulare und damit den mit ihm verbundenen Palatinbogen und den Kiemendeckel zur Seite ab (s. das Schema Abb. 4). So kann ein einziger Muskel bereits den gesamten Mechanismus in Bewegung setzen.

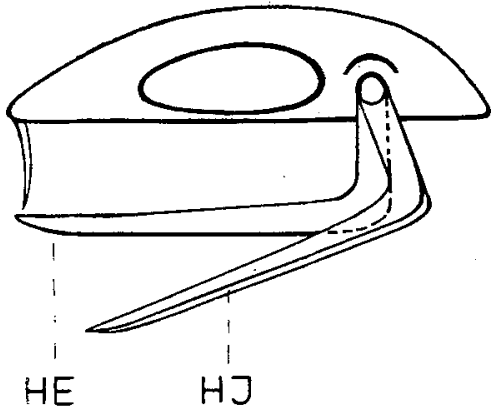

A

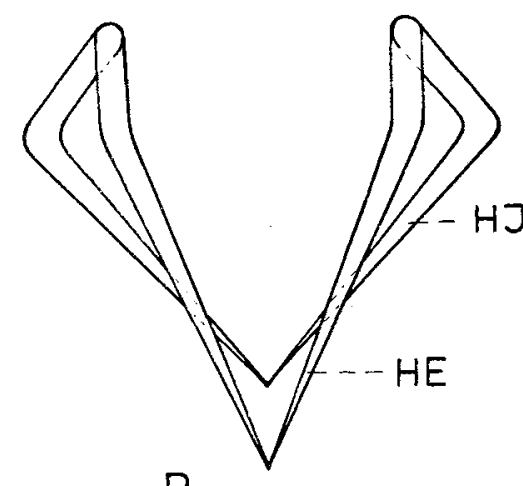

B

Abb. 4. Schema des Hebelsystems des Hyoidbogens bei der Atmung: Senkung und gleichzeitige Abspreizung nach anßen.

A. Seitenansicht B. Ansicht schrïg ron oben (Cranium fortgelassen).

$\mathrm{HE}=$ Hyoidbogen in Exspirationsstellung.

$\mathrm{HI}=$ Hyoidbogen in Inspirationsstellung.

Mit dem Zungenbeinbogen durch die Copulaplatte verbunden sind die Kiemenbögen. Sie werden mit diesen herabgezogen und erweitern die Mundhöhle ebenfalls in ventraler Richtung. An der Spreizung nach außen beteiligen sich diese Bögen in geringem Maße. Es wird später gezeigt werden, daß sie gerade in dieser Bewegung stark beschränkt sind. Die passiven Bewegungen der vier Bogenpaare werden durch ihre eigene Muskulatur aktiv unterstützt.

Werden, wie gesagt, die dorsalen Bogenteile auch bereits passiv durch die Verlagerung der ventralen Teile abduciert, so besitzen sie doch auch eine eigene Muskulatur (die Muskulatur des Palatinbogens und des Hyomandibulare), die ihre Abhebung und die seitliche Erweiterung der Mundhöhle auch aktiv herbeiführen kann. Und wenn die Muskulatur der ventralen Stücke bereits den gesamten Skelettapparat, also auch die dorsalen Teile in Bewegung setzen kann, müßten die Muskeln der dorsalen Glieder ebenfalls die ventralen Stücke in ihren Bewegungen unterstützen. Wenn die Muskeln der Palatinbögen und der Hyomandibularia diese zur Seite führen, spreizen sie auch die dorsalen Enden der Hyalia und kommen ihrem Bewegungsmodus, sich bei Abduktion im ventralen Teil nach hinten abzubiegen, entgegen. Dadurch aber, daß mehrere Muskelgruppen an diesen Bewegungen beteiligt sind, kann der Fisch seinen Bewegungsmechanismus modifizieren, je nachdem es äußere oder innere physiologische Bedingungen erfordern.

Dreierlei scheint durch dies komplizierte Zusammenspiel der Bewegungen erreicht zu werden : Erstens, es sind nur geringe Muskelkräfte nötig, um den Bewegungsmechanismus in Tätigkeit zu setzen. Zweitens, es ist ganz gleich, welche Muskelgruppe diesem Hebelsystem als Triebkraft. dient und an welcher Stelle die Kraft ansetzt, immer wird das ganze Hebelwerk in einheitlichem Sinn bewegt. Und drittens wird eine sehr große Erweiterung der Hohlräume erreicht, ohne daß der Durchmesser der Mundöffnung dabei vergrößert wird. Die Einheitlichkeit dieses Bewegungsmechanismus beruht nun zum großen Teil auf der charakteristischen Konstruktion des Fischschädels, nämlich auf der Hyostylie. Durch sie werden alle Bewegungen auf einen Drehpunkt bezogen, so daf sich jede Kraft in einem Abheben der Backenpartie auswirken muß und eine dorsale Ver- 
schiebung unmöglich wird. Das Hyomandibulare, das Verbindungsglied selbst, ist in seiner Bewegung streng auf ein seitliches Abheben fixiert. Der in der Gelenkkapsel des Squamosum ruhende Gelenkstiel besitzt keine Gelenkkugel, sondern eine Gelenkleiste. Dadurch ist das Knochenglied verhindert, sich kreisförmig nach allen Seiten frei drehen zu können. Seine Bewegungen sind vielmehr auf ein seitliches Abheben begrenzt. Das Anheften des Kieferbogens am Hyomandibulare ermöglicht ferner eine viel stärkere Abhebung, d. h. eine stärkere seitliche Erweiterung der Mundhöhle, als wenn dieser Bogen am Schädel direkt artikulierte.

Bei dyspnoischer Atmung wird der Unterkiefer stärker in den Atmungsrhythmus mit einbezogen, wodurch die Bewegungen mehr den Eindruck von Schnappbewegungen machen. Auf der anderen Seite erleichtert das weite Abspreizen der Backenpartie auch das Verschlingen größerer Beutestücke beim Freßakt, sodaß der Mechanismus des hyostylen Schädels beiden Funktionen des Visceralapparats, der Nahrungsaufnahme und der Atmung gleichzeitig dient.

BAGLION hat die geringe Saugwirkung der Mundhöhle bei geringer Oeffnung und die Bedeutung der Mundklappen in diesem Zusammenhang nicht hervorgehoben, woraus wohl zu schließen ist, daß er die Saugwirkung des gesamten Mechanismus gering einschätzte. Er maß, wie gesagt, der Exspiration, dem heftigen Auspressen des Wassers nach hinten, die größere Bedeutung bei und gab daher seinem Schema den Charakter einer Druckpumpe.

\section{B. Das Schema der Saugpumpe.}

Da BAGLIon's Schema allgemeine Anerkennung fand, wurde der Atmungsmechanismus lange Zeit nicht mehr in den Gesichtskreis wissenschaftlicher Betrachtungen gezogen. Aber vor einigen Jahren hat Woskoвonnikoff (1932) durch eine neue Entdeckung das Interesse an diesen Fragen wieder aufleben lassen. WoskoвоINIKoFf erkannte nämlich,

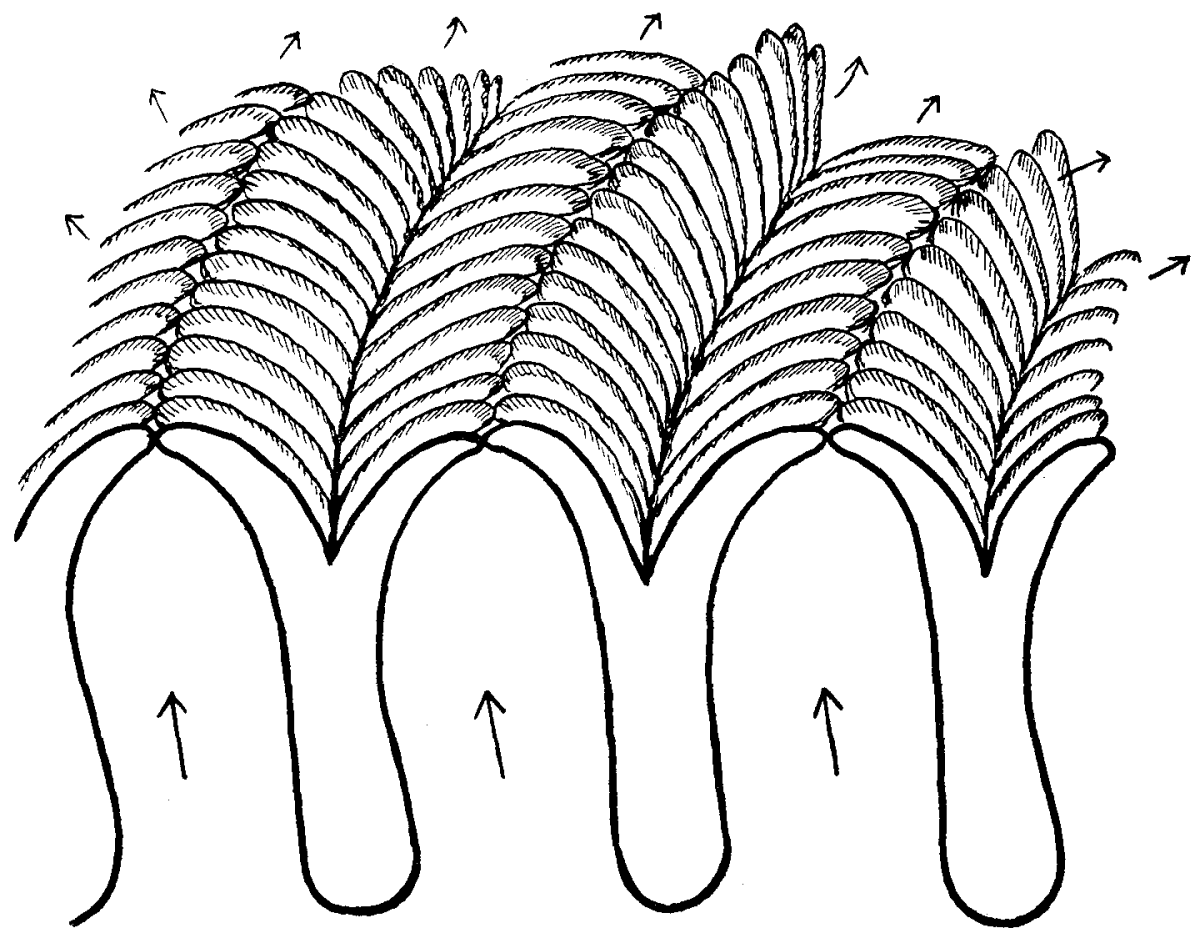

Abb. 5. Schema der Gitterwand der Kiemenblittchen. (Aus Woskoboinikoff: Apparat der Kiemenatmung bei den Fischen.). Die Pfeile geben die Richtung des Atemwasserstroms an.

daß die lateralen Kiemenhöhlen Räume bilden, die von der Mundhöhle durch die Wand der Kiemenblättchen vollkommen getrennt werden. Die Kiemenblättchen hängen nämlich nicht, wie sie in BAGLronI's Schema gezeichnet wurden, schlaff nach hinten in die seitlichen Kiemenhöhlen, sondern bilden in einer charakteristisch gespreizten Stellung ein dichtes Gitter, das die Hohlräume voneinander trennt. Dies ist von seinen Vorgängern 
übersehen worden. Es wurde im Gegenteil stets besonders betont, daß die Kiemenhöhlen mit der Mundhöhle frei kommunizieren. So bietet sich das Bild aber nur am fixierten Material. Ein Blick in die Kiemenhöhle eines lebenden Fischs hätte genügt, um vom Gegenteil zu überzeugen.

WoskoBoINIKOFF hat die Struktur dieses Blättchengitters eingehend studiert und beschrieben. Die Kiemenblättchen sitzen dem Außenrande jedes Kiemenbogens in zwei Reihen auf, wobei jede Reihe je eine Halbkieme des Bogens bildet. Die Halbkiemen jedes Bogens neigen sich voneinander weg, dagegen der Halbkieme des ihnen benachbarten Bogens zu (s. Abb. 5). Die einzelnen Kiemenblättchen sind in Septen geordnet, ihre Stellung ist genau festgelegt, derart, daß die Spitze jedes Blättchens in den Zwischen-

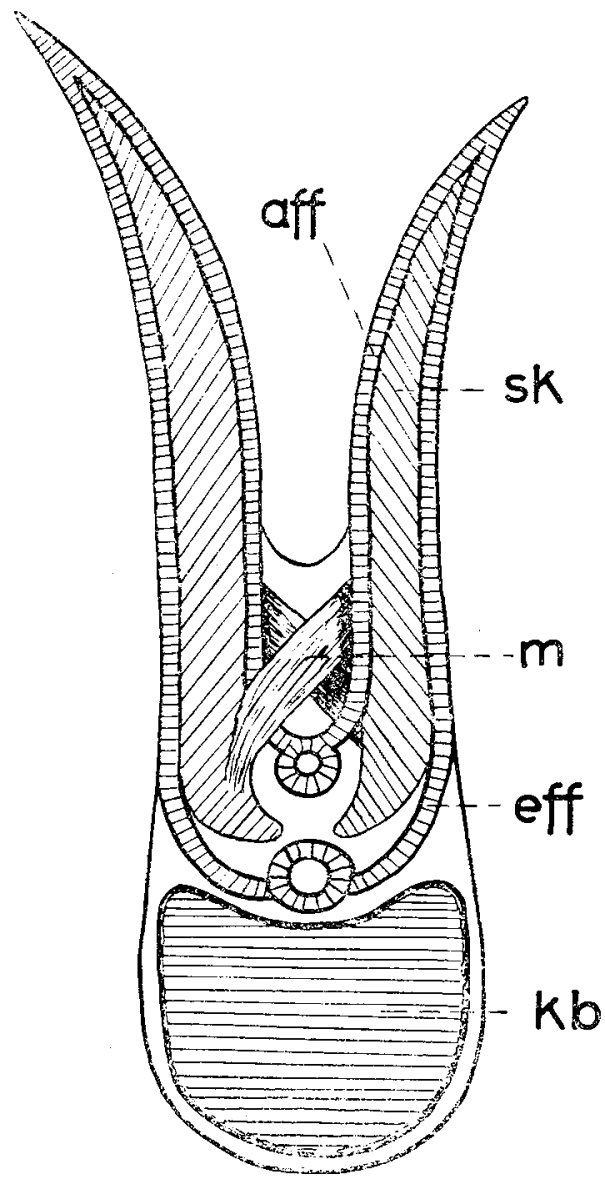

Abb. 6. Struktur des Kiemenblättchens. (Aus WoskobornikofF: Apparat der Kiemenatmung bei den Fischen). Zeichenerklärung: aff́, eff $=$ zufüh rende und abführende Gefäße der Blitttehen, $\mathrm{sk}=$ Skelett, $\mathrm{m}=$ Muskeln, $\mathrm{kb}=$ Kiemenbogen raum zweier ihr gegenüberliegender Blättchen von der Halbkieme des ihr benachbarten Bogens zu liegen kommt. Für diese Fixierung macht WosKoBoINIKOFF den feineren Bau der Blättchen verantwortlich. Ein Blättchen besteht aus einer festen Skelettlamelle aus osteoidem Gewebe, die von der respiratorischen Membran überzogen ist (Abb. 6). Die Lamellen besitzen verbreiterte Basen, die im Bindegewebe des Bogens verankert sind. Diese Knochenelemente geben den einzelnen Blättchen die Festigkeit, in ihrer nach außen geneigten Haltung $\mathrm{zu}$ verharren.

Jede Septe besitzt ein Paar sich kreuzender Muskeln. Dieses soll nicht der Fixierung des Blättchens dienen, sondern die zu- und abführenden Gefäße zwischen den Kiemen verengen und erweitern, also die Rolle eines Kiemenherzens spielen. Es soll dagegen gelegentlich vorkommen, daß diese Muskeln die Blättchen aus ihrer gespreizten Lage anziehen und die Kiemenhöhlen öffnen. Diese Bewegung wird als Reinigungsreflex gedeutet.

Die Blättchenlamellen stehen quer zur Bogenrichtung. Ihre breiten Seiten kehren sich gegenseitig zu. Die respiratorische Membran bildet über diesen eine Reihe von vorspringenden Querleisten, die sich in die Erhabenheiten des Nachbarblättchens verzahnen wie die Zähne zweier Zahnräder. Dadurch bekommt die Kiemenblättchenwand die Struktur eines kompakten Gitters. Die verzahnten Kiemenblattreihen stehen in drei Doppelreihen zwischen den vier Bögen angeordnet. Die äußere Halbkieme des ersten Bogens, die ja keine Partnerin besitzt, berührt mit ihren Kiemenblattspitzen die Außenwand. Der innerste, der vierte Bogen ist bis auf einen kleinen Spalt mit der Schlundwand verwachsen. Die überzählige innerste Halbkieme ragt in dieser Verwachsungszone frei in die laterale Kiemenhöhle.

Diese Gitterkonstruktion der Kiemenblattwand bewirkt natürlich eine sehr intensive Sauerstoffausnutzung des Wassers. WoskobornikofF vermutet, daß sie auch auf den Atemmechanismus Einfluß, haben muß. Er konnte beobachten, daß in der Exspiration auch bei Verhinderung des Mundverschlusses ein Wasserstrom aus den hinteren Kiemenspalten austrat, so daß Mundklappen und Mechanismus der Druckpumpe zur Funktion des Atmungsvorgangs nicht unbedingt notwendig zu seir brauchten. Er übertrug die Rolle der Mundklappen auf die Gitterwand der Kiemenblättchen und veränderte das Druckpumpenschema BAgLIONI's in ein Schema einer Saugpumpe, dessen Triebkräfte in den seitlichen Kiemenhöhlen liegen (Abb. 7).

Sein Gedankengang ist folgender: In der Inspirationsphase heben sich gleichzeitig mit dem Zungenbeinbogen der Kiemendeckel und die. Kiemendeckelhaut ab und erweitern 
auch die lateralen Kiemenhöhlen. Stehen doch ihre Knochenelemente in enger Verbindung mit diesem Knochenbogen. Durch die Wände der Kiemenblättchen wird der Wassereintritt in die Kiemenhöhlen aber verzögert. Dadurch entsteht in ihnen ein Unterdruck, der auf das nachströmende Wasser erhebliche Saugkräfte ausüben muß. Zwei Voraussetzungen müssen zur Entwicklung dieser Saugkräfte erfüllt sein. Erstens dürfen die Kiemenbögen, die sich ja auch während der Inspirationsphase spreizen, nicht so weit auseinander weichen, daß sie die einander zugekehrten Halbkiemen trennen und die Gitterwand öffnen. WoskoBolnikofF weist am Bau der Kiemenbögen des Hechts nach, daß dies nicht der Fall sein kann. Die Bögen jeder Körperseite werden außerdem am dorsalen und ventralen Bezirk durch starke Ligamente zusammengehalten. Die Kiemenbögen des Kabeljau weichen im dorsalen Bezirk vom Bau der Kiemenbögen des Hechts ab, ihr Mechanismus beruht aber auf demselben Prinzip. Die Verhältnisse bei den Plattfischen sind denen des Kabeljau ähnlich (Cole u. Johnstone 1901).
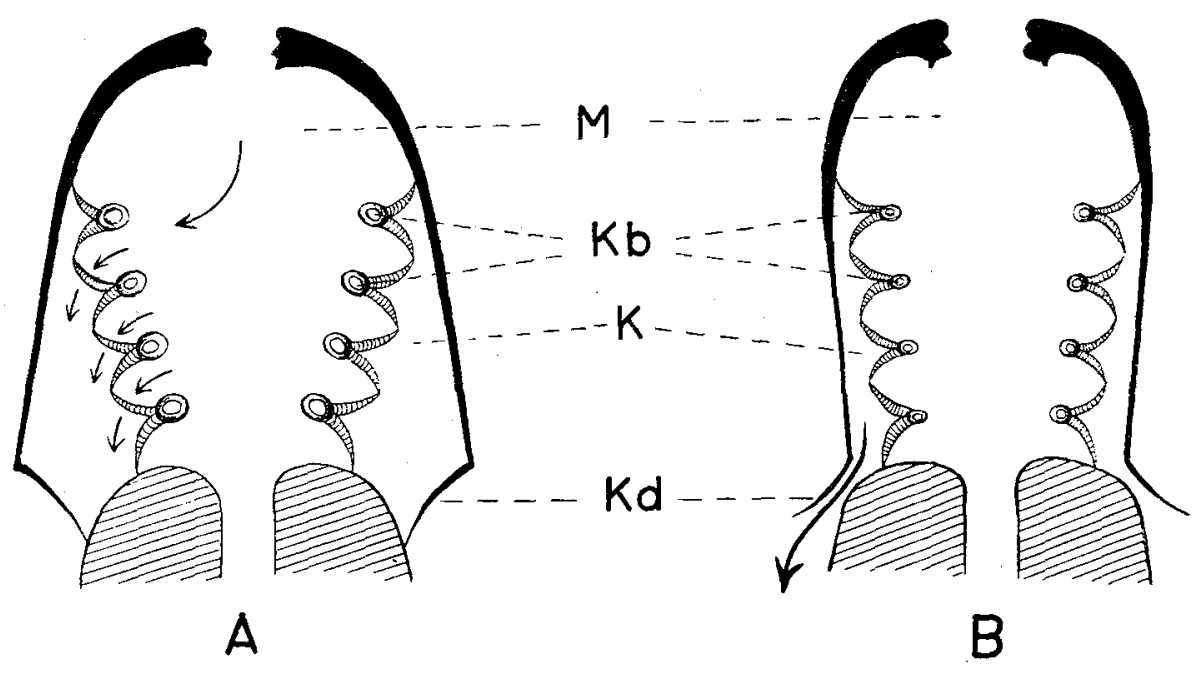

Abb. 7: Atemmechanismus der Teleosteer. Schema der Saugpumpe von WoskoboinikofF. (Nach WoskobornikofF: Apparat der Kiemenatmung bei den Fischen.)

A. Inspiration. B. Exspiration.

Zeichenerklärung: $\mathrm{M}=$ Mundhöhle, $\mathrm{K}=$ seitliche Kiemenhöhlen, $\mathrm{Kb}=\mathrm{Kiemen-}$ bogen, $\mathrm{Kd}=$ Kiemendeckel. Die Pfeile geben die Richtung des ein- bzw. austretenden Wassers an.

Die zweite Voraussetzung zur Entwicklung des Unterdrucks in den seitlichen Kiemenhöhlen ist der Verschluß der Kiemenspalten in der Inspiration. Auch diese ist erfüllt. Die Kiemenspalten werden schon passiv durch den äußeren Wasserdruck geschlossen, der die weiche Haut, die Kiemendeckel und Branchiostegalmembran umsäumt, an den Schultergürtel preßt. WoskoBoInIKoff folgt also hier der BaGLioni'schen Auffassung. Er kennt aber im Bau der Kiemendeckelapparaturen noch eine Reihe weiterer Anpassungen an diese Funktionen. Die Knochenwand des eigentlichen Kiemendeckels sei besonders geeignet, die Kiemenhöhlen gegen den äußeren Wasserdruck zu erweitern. Dagegen fällt dem ventralen Teil, der Branchiostegalmembran, die Aufgabe zu, sich der Rumpffläche dort, wo sie aus der Seiten- in die Bauchfläche übergeht, möglichst eng anzuschmiegen. Diese Funktion muß sie ihrem Bau nach tatsächlich sehr gut erfüllen können. Sie selbst ist weich und schmiegsam, die Knochenstäbe, die sie versteifen, sind elastisch und passen sich in ihrer nach oben und außen gewölbten Form der Rumpfoberfläche besonders gut an. Ich sehe auch in der Art der Anheftung der Knochenstrahlen am Hyale eine Anpassung an diese Funktion. Die ersten drei Strahlen heften sich an der Innenfläche des Hyale an, wobei sie sich der Bauchfläche, die sich ja unter die Membran schiebt, besonders eng anschmiegen können. Die vier letzten Strahlen, denen die Aufgabe zufällt, den Kiemenspalt in der Region der Seitenfläche des Körpers abzuschließen, sitzen der Außenfläche des Hyale auf. Tatsächlich wölbt sich die Seitenfläche des Rumpfes mit dem Schultergürtel etwas gegen die Kiemenhöhlen vor, sodaß die Kiemenhautstrahlen sich ihr auf diese Weise bequemer anlegen können. 
Andererseits hat sich auch der Schultergürtel der Form und Funktion der Branchiostegalmembran angepaßt. Die Kiemenhautstrahlen werden durch die Atmungsbewegungen des Hyale, mit dem sie ja verwachsen sind, über die Rumpffläche hin und her geschoben, in der Inspiration nach hinten, in der Exspiration wieder nach vorn. Hierfür bietet ihnen der Schultergürtel eine ihrem Bewegungsmodus besonders angepaßte Gleitfläche. Der Schultergürtel dient den lateralen Kiemenhöhlen als umrandende Skelettspange. Er neigt sich gegen die Höhle, um seinen äußeren Rand spannt sich die Hautwand der vorderen Rumpfregion, die zugleich die Innenwand der Kiemenhöblen bildet. Die schmale Zone über dem Knochenbogen bildet eine schuppenlose, besonders glatte Fläche, auf der der freie Rand der Branchiostegalmembran mit den Enden der Kiemenhautstrahlen in der Inspiration ungehemmt zurückgleiten kann, ohne sich vom Schultergürtel abzuheben.

Auf jeden Fall ist also auch die zweite Voraussetzung, der Verschluß der Kiemenspalten in der Inspiration, der ja schon von BAGLIonl's Schema gefordert war, erfüllt. Woskoboinikoff's neues Schema der Atmung, das die Arbeitsweise, der von der Mundhöhle getrennten seitlichen Kiemenhöhlen besonders im Auge hat, wirkt sehr überzeugend. Dagegen kann man seine Auffassung über die biologische Bedeutung der komplizierten Gesamtkonstruktion schon aus rein anatomischen Gründen nicht ganz widerspruchslos hinnehmen. Er meint nämlich, die Kompliziertheit des Branchiovisceralapparats hätte den Sinn, daß dieser Apparat bei der Atmung sich stets von einem einzigen Muskel bewegen lassen müsse. Für diesen Atmungsmuskel hielt er den Musculus sternohyoideus. Er konnte allerdings bemerken, daß man an einem toten Fisch durch Verkürzung dieses Muskels den Apparat in der geforderten Weise bewegen kann. Ob es aber wirklich dieser Muskel ist, der im normalen Atmungsakt die Apparatur bedient, ist eine Frage, die hiermit nicht gelöst ist. Bei der Fülle der verschiedenen Muskelgruppen, die dem Tier zur Verfügung stehen und von denen jede für sich den Apparat ja auch wieder in einheitlicher Weise muß bewegen können, erscheint dies unwahrscheinlich. Ich glaubte im Gegenteil, daß die normale Atmungsbewegung den Muskelgruppen der Branchiostegalmembran, des Kiemendeckels und der Visceralbögen eher zuzuordnen ist als dem M. sternohyoideus. Der M. sternohyoideus ist einer der kräftigsten Muskeln des Branchiovisceralskeletts, muß also zu einer großen Arbeitsleistung geeignet sein. Er ist der Maulöffner, der zudem die Mundhöhle so stark erweitern kann, wie es nicht mehr der Atmung, sondern nur dem Verschlingen großer Beutestücke zugute kommen kann. Sollte er nicht seine Hauptaufgabe in der Funktion der Nahrungsaufnahme eher erfüllen als bei der Atmung? Daß er bei forcierter Atmung gelegentlich auch in die Atmungsbewegungen mit eingeschaltet wird, vielleicht notwendig ist, braucht dem nicht zu widersprechen. Die Experimente werden zeigen, daß diese Gedanken bis zu einem gewissen Grad bestätigt wurden.

Aber, wie gesagt, im allgemeinen bedeuteten die Arbeiten Woskoвornikorf's einen großen Fortschritt in der Kenntnis des Atmungsmechanismus. Den experimentellen Beweis seiner Hypothese von der Saugkraft der seitlichen Kiemenhöhlen zu liefern, lag außerhalb seines Aufgabenkreises, da er ja von der rein morphologisch-anatomischen Seite zu den Problemen kam. Er möchte aber selbst die Aufmerksamkeit der Physiologen erneut auf diese Probleme lenken.

Die Aufgabe, WosковогіkofF's Anschaungen über den Atemmechanismus experimentell nachzuprüfen, wurde mir von Herrn Professor v. BudDENBRock im Rahmen der für die Deulsche Forschungsgemeinschaft auszuführenden Arbeiten gestellt. Ich möchte beiden, Herrn Prof. v. BUDDEnBRock für seine liebenswürdige Unterstützung und der Deutschen Forschungsgemeinschaft für die Bereitstellnng der dazı notwendigen Mittel auch an dieser Stelle danken. Ebenfalls danke ich der Biologischen Anstalt auf Helgoland für Ueberlassung eines Arbeitsplatzes, Materialbeschaffung und Unterstützung meiner Arbeitev, iusbesondere dem Direktor der Anstalt, Herrn Professor HaGMeIER.

\section{Die Versuche über den Mechanismus und die Physiologie des Atemapparats.}

Schon die äußerliche Beobachtung des Mechanismus der Atembewegungen mußte die Forscher dazu reizen, auch Experimente darüber anzustellen. Sind doch die Glieder der Branchiovisceralapparatur äußerlich gelegen und also jedem manuellen oder operativen Eingriff leicht zugänglich. Es liegt daher bereits eine größere Zahl auch von experimentellen Untersuchungen über die Atembewegungen vor.

Verschiedene Probleme standen bei diesen Versuchen im Vordergrund. Die Menge des Wassers wurde gemessen, die der Fisch in der Zeiteinheit oder mit jedem Atemzug durch seine Mundkiemenhöhle transportieren konnte (WINTERSTEIN 1908, BAGLIONI 1907). Weiter beobachtete man die Sauerstoffausnutzung 
des an den Kiemen vorbeiströmenden Wassers. WUNDER (1936) macht allerdings mit Recht darauf aufmerksam, daß die Tiere bei den Versuchen oft so unnormalen Verhältnissen ausgesetzt waren, daß die Versuchsergebnisse über die Leistung unter normalen Bedingungen keinen Aufschluß geben könnten. Immerhin geben sie uns ein Bild, was ein Fisch überhaupt mit seinen Atmungsbewegungen zu leisten vermag. In neuerer Zeit haben verschiedene Forscher versucht, diese Mängel auszuschalten nnd die Versuchsbedingungen den normalen Verhältnissen anzupassen (Helga MeYer 1935, Olthoff 1935, Leiner 1938). Sicher sind darin große Fortschritte erzielt worden.

In anderen Untersuchungen wurde die Länge der beiden Atemphasen, der Inspiration und der Exspiration, gemessen. Hier war es wieder BAGLIONI, der die grundlegenden Erkenntnisse gewann. Er übertrug die Bewegungen des Unterkiefers und der Kiemendeckel auf ein Kymographion. Er stellte fest, daß die Inspiration länger als die Exspiration dauerte, eine sehr wichtige Tatsache, weil sie zur Arbeit beider Pumpsysteme in enger Beziehung steht. Auch darüber wurden Versuche angestellt, welche Kompensationsbewegungen der Fisch ausführt, wenn ihm einzelne Glieder der Branchiovisceralapparatur fixiert werden (Lombroso 1907). Aber gerade diese Versuche liegen schon mehrere Jahrzehnte zurück, Sie berücksichtigen nicht das möglicherweise verschiedene Funktionieren der Hohlraumsysteme, weil man ja die Trennung der Hohlräume noch garnicht entdeckt hatte. Lombroso konnte daher auch nicht auf die richtige Interpretation seiner Ergebnisse Kornmen, ja nicht einmal seine Versuche am richtigen Punkt ansetzen. Er muß z. B. mit seiner Mundstenose zu viel Glieder des Atmungsapparats auf einmal lahm gelegt haben. Alle Arbeiten der damaligen Zeit zeichnen sich dadurch aus, daß sie die Bewegungen unter dem Eindruck, der Atmungsapparat sei eine recht einfache Reflexmaschine, zu vorschnell schematisieren wollen. Unter dem neuen Gesichtspunkt des Saugpumpenmechanismus waren aber, wie gesagt, keine Experimente ausgeführt worden.

\section{A. Versuche mit Schollen.}

\section{Beobachtungen der Atemfrequenz und des Bewegungsmodus.}

Den größten Teil der helgoländer Versuche habe ich mit Plattfischen, mit Schollen, vereinzelt auch mit Flundern ausgeführt. Diese Tiere sind durch ihre Lebensweise besonders gut geeignet, weil sie auch unter natürlichen Verhältnissen ruhig am Boden liegen. Man kann sie daher leicht beobachten, ebenso wird der am Boden gefesselte Fisch sich viel weniger durch dies" Fesselung behindert fühlen, als ein normalerweise schwimmender Fisch. Bei den Untersuchungen kam es mir zunächst darauf an, die Arbeitsweise der beiden Hohlraumsysteme getrennt voneinander zu beobachten. Hierfür mußte einmal die Wirkung der seitlichen Kiemenhöhlen, andererseits die Wirkung der Mundhöhle ausgeschaltet werden. Das erreicht man, wenn man dem Fisch den äuBeren Rand der Branchiostegalmembran abschneidet. Er kann die Kiemenspalten nun nicht mehr bei der Inspiration verschließen. Nach der Hypothese müßte sich daher keine Saugwirkung mehr einstellen können, der Atmungseffekt muß also einen großen Ausfall erleiden.

Die Wirkung der Mundhöhle wird ausgeschaltet, wenn man den Mundverschluß durch ein Gummirohr, das man dem Fisch im Maul befestigt, verhindert. Das von der Mundhöhle eingesaugte Wasser muß in der Exspiration wieder zurückströmen, weil es ja in den Mundklappen kein Hindernis findet. Wenn die Mundhöhle wirklich nur so eine untergeordnete Rolle spielt, wie es WoskoBolNikofF vermutet, müßte sich nach dieser Vornahme eine Veränderung der Atmungsintensität oder des Bewegungsmodus der einzelnen Glieder kaum einstellen.

Als Gradmesser der Intensität müssen verschiedene Faktoren berücksichtigt werden: Der Sauerstoffverbrauch, die Atemfrequenz und die "Tiefe" jedes Atemzugs, d. h. der Grad der Erweiterung der Höhlen. Erst alle drei Faktoren in ihrem Verhältnis zueinander können ein Bild über die Leistung des Tieres. unter den verschiedenen Bedingungen geben. Dabei war es besonders schwierig, für die Atemtiefe einen geeigneten Maßstab zu finden. Ich wählte hierzu die Beschreibung des Bewegungsmodus. Es ist nach den morphologischen Ausführungen (S. 245-256) klar, daß bei forcierter Arbeit mehr Glieder in die Bewegung sichtbar mit einbezogen werden als bei normaler Leistung. Die Art und Weise der Bewegung, der Bewegungsmodus ist in den Tabellen mit römischen Ziffern bezeichnet. Dabei bedeutet:

Ziffer I: Bewegung der Branchiostegalmembran. Die Atembewegung der Branchiostegalmembran ist für die Plattfische sehr charakteristisch. Die Inspiration veranschaulichen die Abbildungen $8 \mathrm{a}$ und $8 \mathrm{~b}$, die die Region des Kiemenspalts darstellen. Die Branchiostegalmembran ist durch die Schraffur hervorgehoben (Abb. 8a). Die Branchiostegalstrahlen sind nicht dargestellt. Man muß sie sich in der ventralen Region der Membran denken, sie enden in einer Zone, die als Hautläppchen ïber die Bogenlinie der ausgespannten Membran vorspringt. Hinter diesem Läppchen buchtet die Membran zur dorsalen Verwachsungsstelle mit der Kopfhaut zwischen Kiemendeckel und Cranium konkav aus. Unter dieser Hautbucht, die etwa der Exspirationsklappe von Trigla vergleichbar ist, schießt in der Exspiration das Atemwasser hervor. 
In der Exspiration ist die Branchiostegalmembran fast ganz unter dem Kiemendeckel verschwunden (Abb. 8b), nur das Hautläppchen eben sichtbar. In der Inspiration gleitet dieses nach hinten über den Schultergürtel, wobei es sich etwas ventralwärts verlagert. Die Branchiostegalstrahlen treten unter dem Kiemendeckel hervor, falten die Membran wie einen Fächer auseinander, wobei sie dieselbe etwas auswölben, und schieben sich über den Schultergürtel. Die Hautbucht wird ebenfalls über den Schultergürtel ausgespannt (Abb. 8a).

Ziffer II: Abduktion der Backenpartie. (K= Kiemendeckel allein in Tätigkeit, wobei der Palatinbogen mehr oder weniger stark fixiert gehalten wird.)
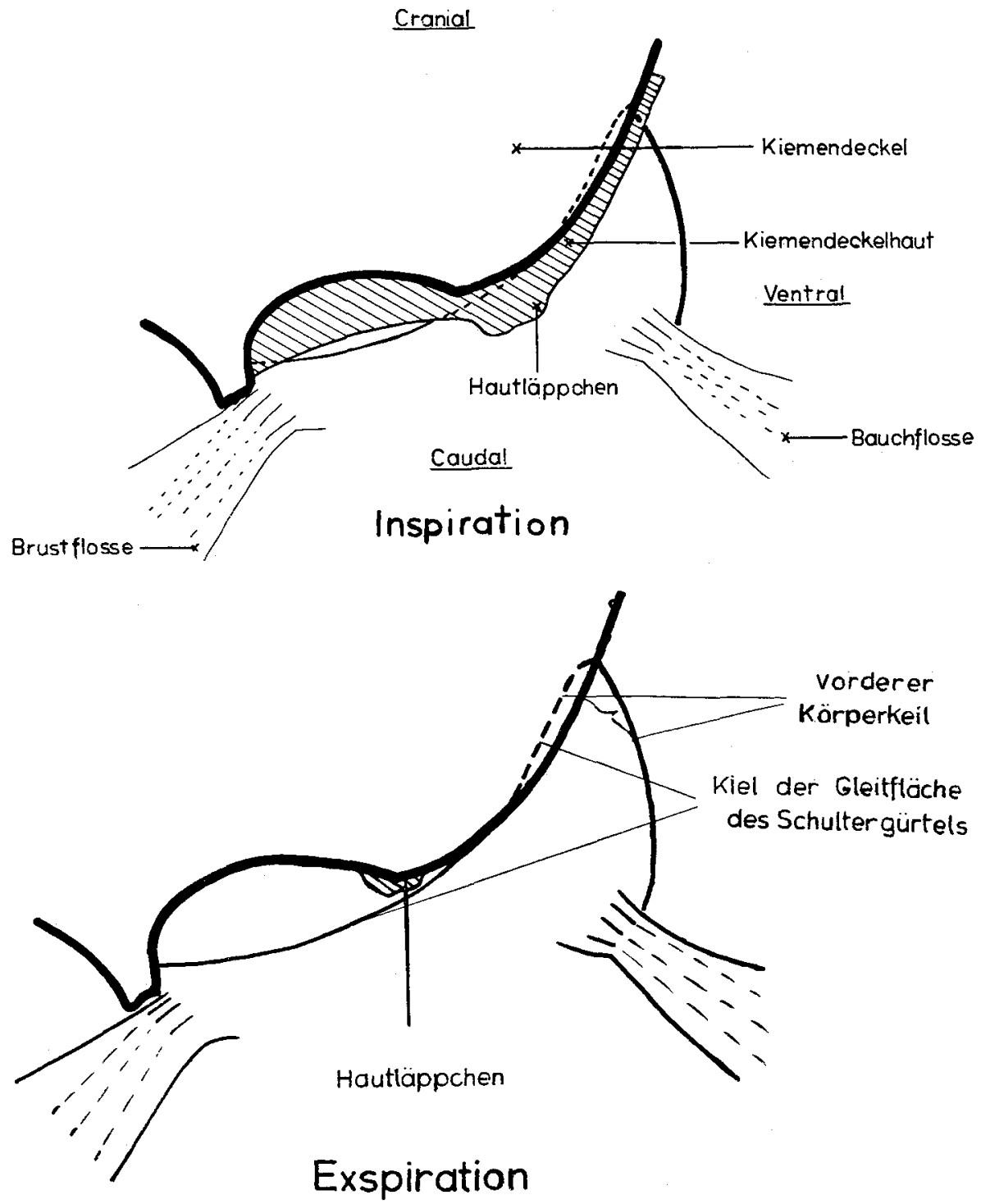

Abb. 8. Kiemenspalte eines Plattfischs.

Ziffer III: Der Zungenbeinbogen wölbt die Kehlhaut aus.

Ziffer IV: Bewegung des Unterkiefers, aktive Schließung der Mundöffnung. Natürlich gibt es Uebergänge zwischen allen Bewegungstypen und es ist nicht leicht zu entscheiden, ob sich ein Glied des Skeletts wirklich in Ruhe befindet. Dies ist nach der Konstruktion des Apparats sogar sehr unwahrscheinlich. Trotzdem bietet die reine Beobachtung immer noch bessere Hinweise auf den Atemtypus, als wenn man das Tier in einen komplizierten Apparat spannt und die Bewegungen auf ein Kymographion 
überträgt, wobei es doch allemal dyspnoisch atmen würde. Die Ergebnisse zeigen sehr deutlich, daß sich die Atmungsweise in beiden Fällen, nach Ausschaltung der seitlichen Kiemenhöhlen, ebenso wie nach Ausschaltung der Mundhöhle geändert haben. Zunächst die Verhältnisse nach Ausschaltung der seitlichen Kiemenhöhlen (Tabelle 1).

\section{Tabelle 1.}

Atmung der Scholle, Frequenz (Atemzüge je Minute) und Bewegungsmodus nach Abschneidung des äußeren Randes der Branchiostegalmembran.

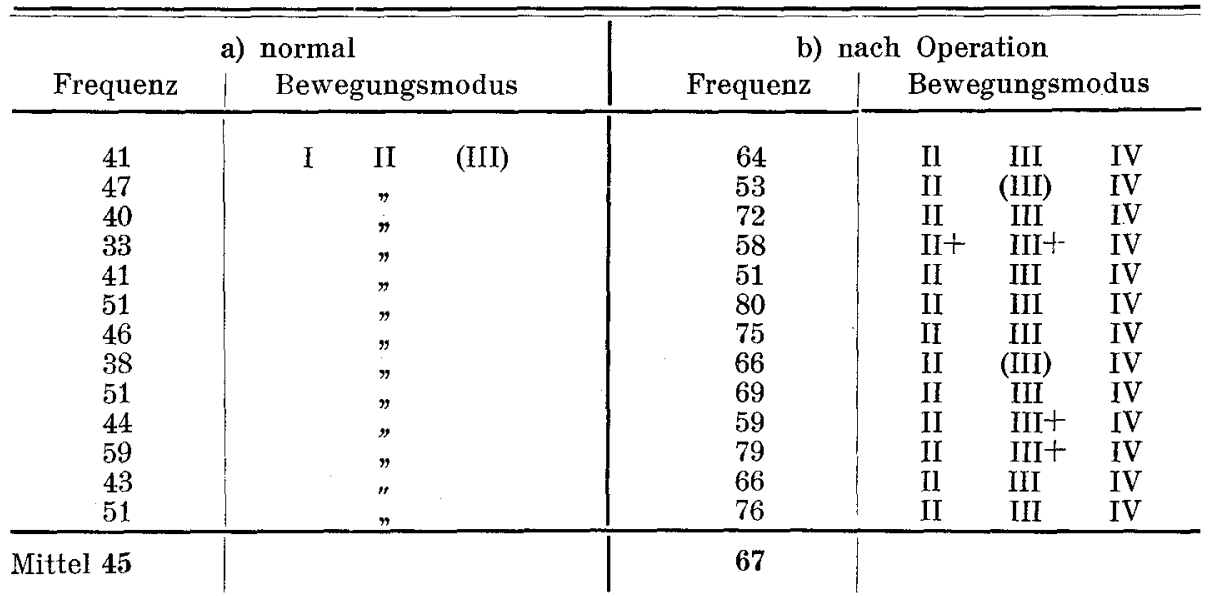

Die Fische steigern die Frequenz; die einzelnen Atemzüge werden also kürzer. Auch die Bewegungsweise wird verändert. Kiemendeckelbewegungen treten zurück gegenüber kräftiger Arbeit des Zungenbeinbogens. Ferner wird der Unterkiefer viel stärker in die Bewegung mit einbezogen als normal, das Maul wird weit geöffnet und fest geschlossen. Zunächst kommt die ventrale Auswölbung der Kehlregion besonders der Erweiterung der Mundhöhle zugute. Das Tier verzichtet weiter bei dieser forcierten Mundhöhlenatmung auf eine volle Ausnutzung der Saugkräfte, die auch die Mundhöhle noch entwickeln kann, zugunsten einer möglichst ergiebigen Füllung des Hohlraums. In der Exspiration dagegen wird die aktive Arbeit der Mundhöhle, das Herauspressen des Wassers noch gesteigert. Das Tier begnügt sich nicht mit dem passiven Spiel der Mundklappen, die den Rückstrom des Wassers verhindern, sondern verschließt das Maul fest, wodurch eine viel stärkere Verengung des vorderen Teiles der Mundhöhle zustande kommt. Die Mundhöhle leistet also die Arbeit einer Druckpumpe ganz im Sinn von BAglion's Schema. Hierfür spricht auch die Steigerung der Atemfrequenz. Die Exspirationsphasen sind auch bei normaler Atmung sehr kurz. Wird nun das Hauptgewicht bei der Atmung auf den Druckpumpenmechanismus, also auf die Exspiration gelegt, so müssen sich die Gesamtphasen verkürzen, die Frequenz muß sich steigern.

Tabelle 2 zeigt die Ergebnisse nach Ausschaltung der Mundhöhle. Hierbei war das Tier ganz auf die Arbeit der seitlichen Kiemenhöhlen allein angewiesen.

Tabelle 2.

Atmung der Scholle, Frequenz und Bewegungsmodus nach Anbringung eines Gummirohrs in der Mundöffnung.

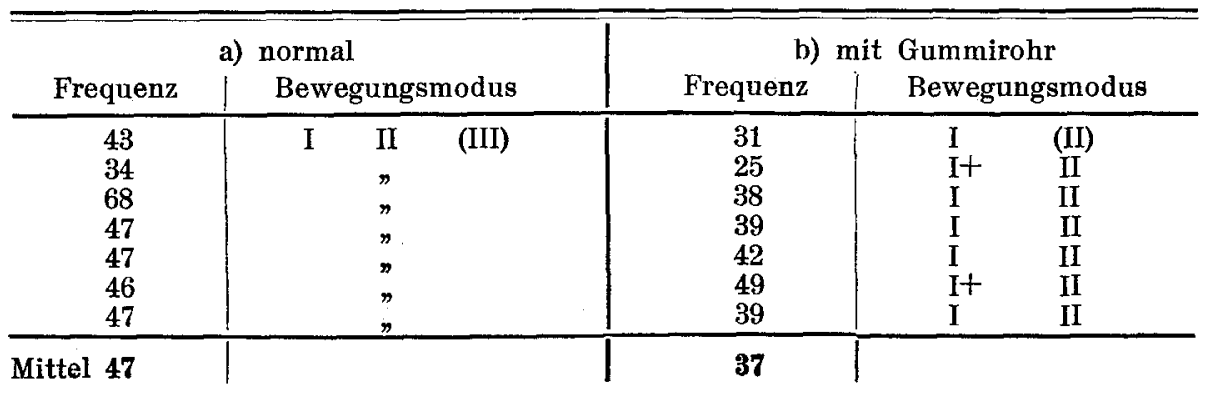


Es trat in allen Punkten das Gegenteil ein von dem, was wir nach Ausschalten der Kiemenhöhlen beobachten konnten. Die Frequenz wird vermindert, die einzelnen Atemzüge werden verlängert. Im Bewegungsmodus trat gerade die Arbeit der Kiemendeckel und der Branchiostegalmembran hervor, die sich sehr weit über den Schultergürtel schob. Eine Deutung dieser Ergebnisse fällt nicht schwer. Der Fisch hat mit seinen seitlichen Kiemenhöhlen Saugarbeit geleistet. Die starke Ausspannung der Branchiostegalmembran deutet das an, die Verlangsamung der Frequenz beweist es. Saugarbeit ist natürlich Inspirationsarbeit. Die Verlängerung der Gesamtphase bei gesteigerter Saugtätigkeit entspricht wieder der längeren Inspirationsphase der normalen Atmung.

In der Exspiration tritt genau wie bei normaler Atmung ein Wasserstrom aus den Kiemenhöhlen nach hinten aus. Ein Beweis, daß die seitlichen Kiemenhöhlen die Atmungsarbeit auch allein zu leisten vermögen. Wenn sich die Kiemenhöhlen verengen, findet das Wasser in den Kiemenblattgittern einen Widerstand. Es entweicht durch die geöffneten Spalten nach hinten. Es ist aber auch ein Restwasserstrom zu beobachten, der in umgekehrter Richtung aus der Mundöffnung wieder ins Außenmedium tritt, ein Zeichen, daß die Glieder der Mundhöhle bei forcierter Saugpumpenarbeit nicht vollkommen fixiert gehalten werden.

Im Sauerstoffverbrauch haben alle Fische -- normale und solche, denen die Mundhöhle und die seitlichen Kiemenhöhlen außer Funktion gesetzt waren - keine Unterschiede gezeigt, jedes Hohlraumsystem allein vermag also so viel Wasser an den Kiemen vorbeizuführen, dafs der Fisch sein Blut mit Sauerstoff sättigen kann.

Beim normalen Atmungsakt wirken Mundhöhle und seitliche Kiemenhöhlen zusammen und ergänzen sich gegenseitig. Die Mundhöhle leistet in der Hauptsache Exspirationsarbeit, sie kann als Druckpumpe, die seitlichen Kiemenhöhlen leisten Inspirationsarbeit, sie können als Saugpumpen aufgefaßt werden. ${ }^{1}$ )

Man wird sich an dieser Stelle Gedanken darüber machen, wie die verschiedenen Pumpsysteme im Lebensraum der Tiere wirken mögen. Liegt das Hauptgewicht der Atmung auf der Arbeit der Mundhöhle, also auf dem Druckpumpenmechanismus, so wird der Fisch eine ausgiebigere Füllung seiner Hohlräume mit Wasser erzielen als normal; denn wir sahen ja, daß die Erweiterung der Hohlräume, besonders der umfangreichen Mundhöhle bei Druckpumpenarbeit größer ist. Dagegen wird das Wasser, das dem Fisch zur Sauerstoffentnahme bei dieser Pumparbeit zur Verfügung gestellt wird, nur aus der nächsten Umgebung der Mundhöhle stammen, weil hierbei von allen Seiten her Wasser in das geöffnete Maul hineinstürzen muß. Es ist dabei leicht möglich, daß der Fisch bereits verbrauchtes, sauerstoffärmeres Wasser in seine Hohlräume noch einmal saugt. Bei forcierter Saugpumpenarbeit kann der Fisch nur geringere Mengen Wasser in seine Hohlräume aufnehmen, da sie sich ja nicht mehr so stark erweitern wie bei ausgesprochener Mundhöhlenatmung. Dafür entsteht durch den entwickelten Unterdruck ein starker Sog, der das Wasser aus viel weiterer Entfernung zum Fisch heransaugt. Saugpumpenarbeit muß also dem Tier ein frischeres, stets unverbrauchtes Wasser zur Verfügung stellen. Kein Wunder, daß dies Arbeitssystem in seiner extremen Form verwendet wird von Fischen, die selten ihren Aufenthaltsort wechseln, besonders von Bodenfischen.

\section{Direkter Nachweis der Saugleistung der seitlichen Kiemenhöhlen.}

Die Saugtätigkeit der seitlichen Kiemenhöhlen, ihre Trennung von der Mundhöhle, ist, wie gesagt, erst vor einigen Jahren aus den anatomischen Verhältnissen erschlossen worden. Es war daher mein Bestreben, die Saugarbeit nicht nur indirekt aus Frequenz und Bewegungsmodus zu erschließen, sondern direkt nachzuweisen und zu messen. Der direkte Nachweis ist mir mit einer Apparatur gelungen, durch die ich das Tier gegen das hydrostatische Gefälle Wasser saugen ließ. Die Versuchsanordnung zeigt eine Skizze (Abb. 9). Der Fisch liegt im Aquarium auf einem Ziegelstein festgebunden. Eine Schlauchleitung, die ihm im Maul befestigt ist, führt in einen Zylinder, der neben dem Aquarium aufgestellt ist und aus dem der. Fisch sein Atemwasser saugen soll. Die Schlauchleitung muß in der Mundöffnung wasserdicht abgebunden sein. Dies erreicht man leicht, wenn man ihm um die Lippenwülste eine Garnschlinge legt und sie um das ins Maul gesteckte Schlauchende fest anzieht. Auf diese Weise kann kein Wasser

1) Anmerkung: Zu ähnlichen Ergebnissen kommt ans theoretischen Erwägungen VAN DAM (1938), dessen Arbeiten mir freundlicherweise während der Zusammenstellung dieser Arbeit von Herrn Professor HAZELHOFF, Groningen, zugeschickt wurde. 
zwischen Mundwandung und Schlauchende seitwärts in die Mundhöhle eindringen. Bei dieser Art Abbindung konnte sich auch noch der Zungenbeinbogen frei bewegen, nur der Unterkiefer war fixiert. In die Schlauchleitung hatte ich ein Rückschlagventil eingeschaltet, das den Rückstrom des Atemwassers in der Exspiration verhindern sollte, wenn sich der Wasserspiegel im Zylinder schon zu weit erniedrigt hatte.

Mit jedem Atemzug erniedrigte sich der Wasserspiegel, die Saugleistung mußte also mit jedem Atemzug gesteigert werden. Es sollte festgestellt werden, bis zu welchem Niveauunterschied der Fisch überhaupt Wasser saugen konnte. Den Gang der Versuche zeigen am besten einige Protokolle.

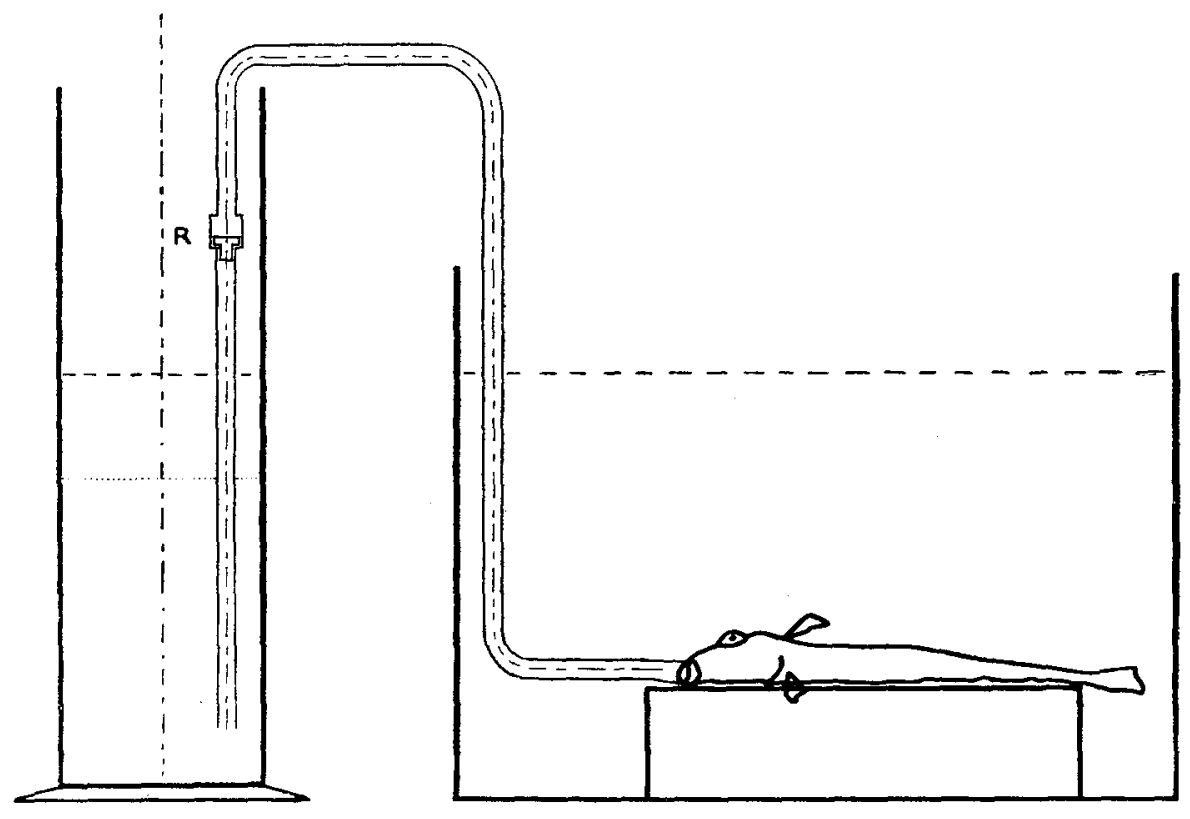

Abb. 9. Plattfisch, aus einem Zylinder Wasser saugend. $\mathbf{R}=$ Rückschlagventil.

Versuchstier: Flunder $25 \mathrm{~cm}$.

\section{Protokoll.}

Vorversuch: Es wird nach jedem Atemzug der Niveauunterschied der Wasserspiegel durch Nachheben des Zylinders wieder ausgeglichen.

Der Fisch saugt je zweimal:

$50 \mathrm{ccm}$ Wasser in 5 Minuten $=10 \mathrm{ccm}$ Wasser in der Minute.

Versuch: Der Standzylinder wird nicht nachgehoben: Ein Rückschlagventil wird in die Schlauchleitung nicht eingeschaltet. Der Fisch atmet, bis der Niveauunterschied der beiden Wasserspiegel $1,2 \mathrm{~cm}$ erreicht. Darauf strömt das Wasser in der Exspiration wieder in den Zylinder zurück.

Nun wird der äußere Rand der Branchiostegalmembran abgeschnitten. Der Fisch saugt auch bei gleichem Niveau der beiden Wasserspiegel mit keinem Atemzug Wasser aus dem Zylinder. Es tritt Atemnot ein.

\section{Protokoll.}

Versuchstier: Flunder $26 \mathrm{~cm}$.

Versuch: Rückschlagventil eingeschaltet.

Tier saugt in fünf Minuten etwa $20 \mathrm{ccm}=4 \mathrm{ccm}$ in der Minute. Es saugt bis der Niveauunterschied $2,2 \mathrm{~cm}$ erreicht hat. Darauf setzt dyspnoische Atmung ein. Hierbei wird der Kiemendeckel auch während der Inspiration gespreizt. Offenbar herrscht die Tendenz vor, Wasser von hinten durch die Kiemenspalten an die Kiemenblättchen herantreten zu lassen. Nach Entfernung des äußeren Randes der Branchiostegalmembran kann der Fisch ebenfalls kein Wasser mehr saugen. 
Als Gesamtergebnis dieser Untersuchung bringe ich eine Zahlenreihe.

\begin{tabular}{c|c}
\hline & $\begin{array}{c}\text { Flundern von } \\
\text { cm Länge }\end{array}$ \\
\hline & saugten bis zu einem Niveauunterschied von \\
21 & 1,7 \\
25 & 2,8 \\
25 & 2,3 \\
25 & 3,2 \\
26 & 2,2 \\
26 & 2,2 \\
\hline Mittel & $2,4 \mathrm{~cm}$
\end{tabular}

Nach Abschneidung des äußeren Randes der Branchiostegalmembran konnte kein Tier mehr Wasser aus dem Zylinder saugen.

Mit dieser Versuchsanordnung konnte also an Plattfischen die Richtigkeit von Wosковогnikoff's Auffassung über die Arbeitsweise der lateralen Kiemenhöhlen bewiesen werden. Diese Hohlräume entwickeln für ihre Größe recht erhebliche Saugkräfte. Das ist - entsprechend Wозковоглікоғн's Anschauung - nur möglich, wenn die Kiemenspalten von der Branchiostegalmembran während der Inspiration vollständig verschlossen gehalten werden. Künstliche Oeffnung der Höhlen verhindert die Entwicklung der Saugkraft.

\section{Quantitative Leistung jedes Atemzugs.}

Um zu quantitativen Vergleichszahlen zu kommen, die uns ein Bild über die Saugleistung der Tiere geben können, benutzte ich eine andere Apparatur. Ich ließ mir ein Glasrohr zu einer Glasschlange biegen und diese auf einen Rahmen montieren. Vor

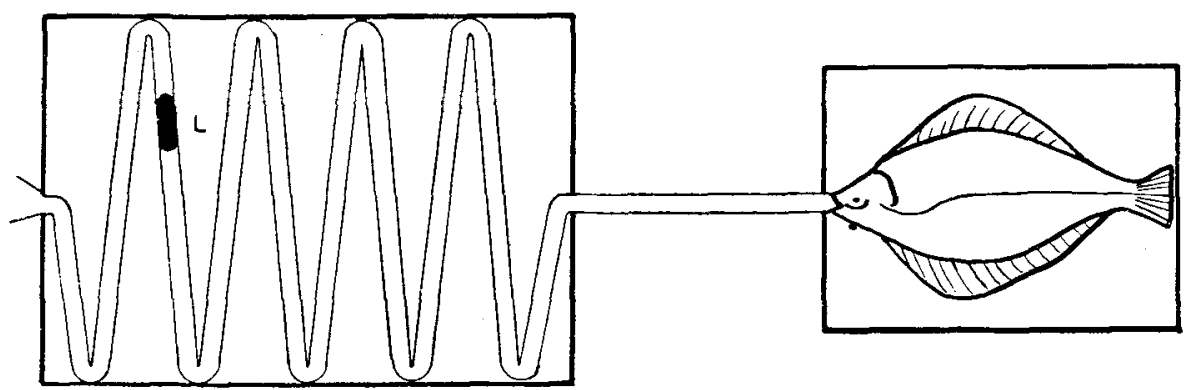

Abb. 10. Plattfisch, Wasser durch die Glasschlange saugend.

$$
\mathrm{L}=\text { Luftblase. }
$$

den Apparat, der in ein großes Becken mit Seewasser gelegt wurde, wurde der auf einen Ziegelstein gefesselte Fisch gespannt, ganz ähnlich wie im Zylinderversuch (Abb. 10). Er mußte also das Atemwasser durch das Glasrohr saugen. Am offenen Ende war das Glasrohr zu einem Trichter erweitert, durch den ich mit Hilfe eines Röhrchens eine Luftblase in die Glasschlange einblasen konnte, die nun mit dem Atemstrom zum anderen Ende der Glasschlange hinwanderte. War sie dort angelangt, hatte der Fisch gerade den Inhalt der Glasschlange durch seine Kiemen gesaugt. Dieser Inhalt war bekannt. Er betrug $87 \mathrm{ccm}$. Ich konnte die Zeit mit der Stoppuhr abmessen, die die Luftblase zu ihrer Wanderung brauchte, schließlich konnte ich die Atemzüge je Minute zählen und daher die Menge des durchgesaugten Atemwassers je Minute und je Atemzug berechnen.

Äls Atemwasser wurde annähernd sauerstoffgesättigtes, frisches Seewasser benutzt. Es mußte auch bei möglichst gleicher 'Temperatur' gearbeitet werden, um vergleichbare Werte zu erlangen. Die Temperatur betrug, wenn nichts anderes erwähnt ist, $15-17^{\circ} \mathrm{C}$. Ein Protokoll zeigt Verlauf und Ergebnis eines solchen Versuchs.

Der Fisch hat erhöhte Saugarbeit geleistet. Die Frequenz ist noch stärker erniedrigt, als wenn man ihm lediglich die Funktion der Mundhöhle nimmt (Verhinderung des Mundverschlusses durch ein Gummirohr). Im Bewegungsmodus fällt die sehr genaue Fixierung des Palatinbogens auf. Der Kiemendeckel, d. h. Operculum und Suboperculum arbeiten selbständig. Deutlich ist zu erkennen, daß sie sich bei der Abduktion gegen das Präoperculum einwinkeln. Der Fisch hat, wenn er das Wasser durch die Glasschlange saugt, 


\section{Protokoll.}

Scholle $22 \mathrm{~cm}$. 8. XI. $10 \mathrm{Uhr}$. Tier vor die Glasschlange gespannt.

\begin{tabular}{|c|c|c|c|c|}
\hline $\begin{array}{l}\text { Versuch } \\
\text { Nr. }\end{array}$ & $\begin{array}{l}\text { Atemfrequenz } \\
\text { je Minute }\end{array}$ & $\begin{array}{l}\text { Zeitdauer, in der die Luft- } \\
\text { blase von einem Ende zum } \\
\text { andern wandert: }\end{array}$ & \begin{tabular}{c|c|}
\multicolumn{2}{c|}{ Der Fisch saugte } \\
ccm Wasser & $\begin{array}{l}\text { ccm Wasser } \\
\text { je Minute }\end{array}$ \\
\end{tabular} & $\begin{array}{l}\text { Bewegungs- } \\
\left.\text { modus }{ }^{1}\right)\end{array}$ \\
\hline $\begin{array}{l}1 \\
2 \\
3 \\
\\
4 \\
5 \\
6\end{array}$ & $\begin{array}{l}21 \\
22 \\
37 \\
\\
20 \\
47\end{array}$ & $\begin{array}{l}7^{\prime} 77^{\prime \prime} \\
8^{\prime} 07^{\prime \prime} \\
\text { Tier von der Glasschlang } \\
\text { durch kurzes Gummirohr } \\
8^{\prime} 30^{\prime \prime} \\
\text { Äußerer Rand d. Branchiost } \\
\text { Tier wieder vor die Glas } \\
\text { blase wandert nicht mehr }\end{array}$ & \begin{tabular}{c|c|}
12,0 & 0,6 \\
10,7 & 0,5 \\
abgeschaltet; & saugt nur \\
10,2 & 0,5 \\
galmembran abgeschnitten. \\
chlange geschaltet.
\end{tabular} & $\begin{array}{l}I+I I K \\
I+I I K \\
I+I I \text { normal } \\
I+I I K \\
\text { dyspnoisch }\end{array}$ \\
\hline
\end{tabular}

einen Reibungswiderstand zu überwinden. Die Ergebnisse können also nicht die Atmung der normalen Verhältnisse widerspiegeln. Aber dieser Reibungswiderstand ist während des ganzen Versuchs gleichmäßig hoch, so daß man mit dieser Apparatur vergleichbare Werte erhalten kann. Sehr schön zeigen die verschiedenen Versuche, in denen das Tier an der Glasschlange atmen mußte, annähernd gleichmäßige Leistungen des Fischs. Die gewonnenen Atemwerte gibt Tabelle 3 wieder.

Tabelle 3 .

Atemleistung der Scholle beim Saugen einer Wassersäule durch die Glasschlange.

\begin{tabular}{|c|c|c|c|c|c|}
\hline Tier & Länge in $\mathrm{cm}$ & Frequenz & $\begin{array}{c}\text { Dauer der } \\
\text { Luftblasenwanderung }\end{array}$ & $\begin{array}{l}\text { Tier saugt } \\
\text { je Minute }\end{array}$ & $\begin{array}{l}\text { cm Wasser } \\
\text { je Atemzug }\end{array}$ \\
\hline $\begin{array}{r}1 \\
2 \\
3 \\
4 \\
5 \\
6 \\
7 \\
8 \\
9 \\
10 \\
11 \\
12 \\
13 \\
14 \\
15 \\
16 \\
17 \\
18\end{array}$ & $\begin{array}{l}19 \\
19 \\
20 \\
20 \\
21 \\
21 \\
21 \\
22 \\
22 \\
22 \\
23 \\
23 \\
23 \\
23 \\
23 \\
24 \\
26 \\
30\end{array}$ & $\begin{array}{l}21 \\
26 \\
17 \\
21 \\
24 \\
17 \\
15 \\
18 \\
18 \\
14 \\
19 \\
14 \\
14 \\
13 \\
24 \\
19 \\
11 \\
14\end{array}$ & 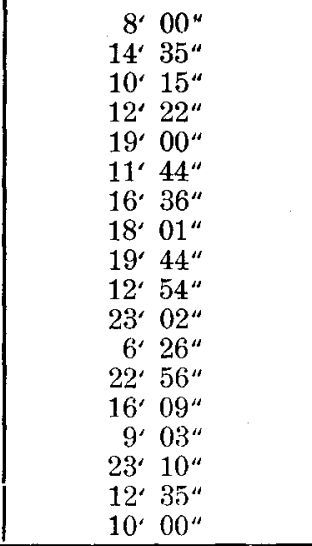 & $\begin{array}{r}10,9 \\
6,0 \\
8,5 \\
7,0 \\
4,6 \\
7,4 \\
5,3 \\
4,8 \\
4,4 \\
6,7 \\
3,8 \\
13,6 \\
3,6 \\
5,1 \\
9,6 \\
3,7 \\
7,0 \\
8,7\end{array}$ & $\begin{array}{l}0,52 \\
0,23 \\
0,50 \\
0,33 \\
0,19 \\
0,44 \\
0.36 \\
0,27 \\
0,25 \\
0,48 \\
0,20 \\
0.97 \\
0,26 \\
0,39 \\
0,40 \\
0,19 \\
0,63 \\
0,62\end{array}$ \\
\hline & & & & $\begin{array}{c}6,7 \\
(13,6-3,6)\end{array}$ & $\begin{array}{c}0,40 \\
(0,97-0,19)\end{array}$ \\
\hline
\end{tabular}

Sie zeigt, daß die Schwankungen der Saugleistung bei den einzeInen Tieren groß gewesen sind. Es fallen zunächst relativ hohe Werte ins Auge. Sie stammen offenbar von Tieren, die in Erregung gewesen sind und stärker geatmet haben als normal. Man findet aber auch sehr niedrige Werte, besonders ausgeprägt niedrig in der zweiten Rubrik, die die Wassermenge jedes Atemzuges zur Darstellung bringt. Diese Tiere haben also mit jedem Atemzug nur wenig Wasser durch die Glasschlange transportieren können. Die Ursache dieser Fehlleistung wirft ein helles Licht auf das Funktionieren der gesamten Atmungsapparatur. Die Fische haben sich in diesen Versuchen nämlich nicht auf die extreme Saugarbeit der seitlichen Kiemenhöhien eingestellt, sondern in der Inspiration die Mundhöhle ebenfalls erweitert. In der Exspiration wurde daher ein Teil des eingesaugten Wassers aus der Mundöffnung wieder ausgestoßen, was man an einem Zurück-

1) Erklärung siehe S. 257 u. 258. 
wandern der Luftblase während der Exspiration beobachten konnte. Bei Saugarbeit allein wandert die Blase in ruckweisen Abständen nach vorn, ohne in der Exspiration wieder ein Stück zurückzuweichen. Diese Fehlleistungen zeigen doch wieder, wie wichtig für den normalen Atmungsakt die Mundhöhle und ihr Druckpumpenmechanismus sein mag. Denn bei normaler Atmung ist etwas ähnliches wie die Fixierung des Palatinbogens und die Ausschaltung der Mundhöhle nie zu beobachten.

Einige Tiere haben die extreme Saugarbeit an der Apparatur im Laufe des Versuchs erst „lernen“ müssen. Die ersten Atemzüge waren dann für das Tier sehr unergiebig. Die Luftblase wanderte hier wenigstens anfangs während der Exspiration wieder ein Stück zurück. Zahlenmäßig ist die langsame „Erlernung“ des zweckmäßigsten Atmens dadurch zu erfassen, daß man die erste und die zweite Hälfte der Luftblasenwanderung mit der Stoppuhr getrennt abstoppt. Ich bringe einen dafür besonders kennzeichnenden Versuch.

Das Tier saugte:

in der 1. Hälfte der Versuchszeit

$4 \mathrm{ccm}$ je Minute $0,25 \mathrm{ccm}$ je Atemzug

in der 2. Hälfte

$6,1 \mathrm{ccm}$ je Minute $0,48 \mathrm{ccm}$ je Atemzug

Vielfach haben die Tiere, wenn sie noch nicht „gelernt" hatten, extreme Saugarbeit zu leisten, schneller geatmet, was ja nach dem Prinzip des gesamten Mechanismus nur zu erwarten wäre. Hierfür wieder eine Zahlenreihe:

Atemzüge je Minute (Tier atmet vor der Glasschlange):

29242525

Luftblase wandert zurück.
19222221 usw. gleichbleibend. Luftblase wandert nicht zurück.

Auch diese Beobachtungen sind ein Hinweis darauf, daB Saugarbeit allein der normalen Atmung nicht entspricht.

Es liegen von WINTERSTEIN (1908) Atemmessungen an Leuciscus und Perca vor. 80-170 gr schwere Tiere atmeten mit jedem Atemzug etwa $0,5 \mathrm{ccm}$ Wasser, was dem Schollenmittel also annähernd entspricht. (Schollen von etwa $20 \mathrm{~cm}$ Länge wiegen $90-120 \mathrm{gr}$.) Da sie aber eine viel höhere Atemfrequenz aufwiesen, war die Wassermenge, die sie an ihren Kiemen vorbeiführten, in der Zeiteinheit viel größer. Sie atmeten $60 \mathrm{ccm}$ Wasser je Minute, etwa das zehnfache der Scholle. Diese Werte werden über dem normalen Mittel liegen, weil die Tiere in ihrer komplizierten und unbiologischen Apparatur in großer Erregung gewesen sein dürften. Die Schollenmittel dagegen werden zu niedrig sein. Die Tiere haben unter erschwerten Bedingungen geatmet. Außerdem mußte die Mundhöhle, im normalen Atmungsakt ein wichtiger Mechanismus für die Atemleistung, ausfallen. Die Schollenwerte werden aber den Normalwerten näher liegen, weil die Tiere bestrebt. sind, den Minimalwert des Sauerstoffverbrauchs aufrecht zu erhalten.

\section{Die Bedeutung verschiedener Branchiovisceralmuskeln für den Atmungsakt.}

An der Glasschlange konnte die Funktion verschiedener Muskelgruppen und Glieder des Atmungsapparats, denen auf Grund ihres anatomischen Baues bereits bestimmte Rollen zugewiesen waren, auch experimentell nachgeprüft werden.

Ueber die Bedeutung der verschiedenen Muskeln liegt auch in der Literatur eine größere Anzahl von Diskussionen vor. Sie alle schlielen sich anatomischen Intersuchungen an. Ich erwähnte, dark WoskoвorsikofF den Musculus sternohyoideus für den Hauptatemmuskel hielt, - schon nach den anatomischen Verhältnissen eine zu einseitig anmutende Auffassung. Bacilont hob die Bedeutung der Muskeln der Branchiostegalmembran für bodeulebende Fische hervor. Bekannt ist BorcEA's Bild dieser Membranmuskeln von Trachinus (BABÁ 1931). Alle Muskelanatomen: VeTTER 1878. HoLMQUIST 1910, B.1BÁK 1931, in neuerer Zeit SchMiTT (nach NoRMAN 1934; die Ausführungen des Letzteren sind gerade für liese Arbeit sehr wichtion), führen eigene Gedanken über die Funktion der versehiedenen Muskeln aus - eine anatomische Muskelstudie, welche ihre Funktion nicht berücksichtigt, ist ja garnicht denkbar.

Aber auch hier können anatomische Betrachtungen allein und Bewegungsstudium am Skelett eines toten Tieres über die Funktion im Leben nichts endgültiges aussagen. NORMAN bedauert mit Recht, daß ScHMITT seinen morphologischen Beschreibungen der Branchiovisceralmuskulatur keine physiologischen Experimente an die Seite gestellt hat. Gerade die Glasschlange schien für eine solche experimentelle Untersuchung der Muskeln besonders geeignet. Durchschneidet man dem Fisch eine Muskelgruppe, die 
wichtige Glieder der Atmungsapparatur bedient, wird man wohl erwarten dürfen, daß er jetzt nur noch geringe Atmungsarbeit leisten, d. $h$. weniger Wasser durch seine Atmungshöhlen saugen kann. Diese Verminderung der Leistung wird sich an der Glasschlange an einer Verlangsamung der Luftblasenwanderung zahlenmäßig feststellen lassen. Aber auch dann, wenn das Tier nun eine andere Muskelgruppe zuhilfe nimmt und Kompensationsbewegungen ausführt, wird man an der Veränderung des Bewegungsmodus bei etwa gleichbleibender Luftblasenwanderung Rückschlüsse auf die Funktionen der durchschnittenen Muskeln ziehen können. Schließlich wird nach Durchschneidung mehrerer Muskeln gleichzeitig die Bedeutung des Zusammenspiels der verschiedenen Muskelgruppen erkannt werden können.

\section{a) Anatomie der Atmungsmuskeln.}

Vor Beschreibung der Operationsversuche wird es wieder nötig sein, einen Blick auf die anatomischen Verhältnisse der Muskeln zu werfen, die ich in den Gesichtskreis meiner Beobachtungen zog. Der Musculus sternohyoideus als erster, existiert bei den Plattfischen nicht als einheitlicher Muskelstrang. Die Muskelgruppe der Ventralregion, die ihm funktionell entspricht, zeigt recht komplizierte Verhältnisse. (Abb. 11.) Sie steht im engen Zusammenhang mit dem Intercleithrum. Dies ist ein zartes Knochenblatt in der morphologischen Medianebene zwischen die Knochen des Schultergürtels und in die

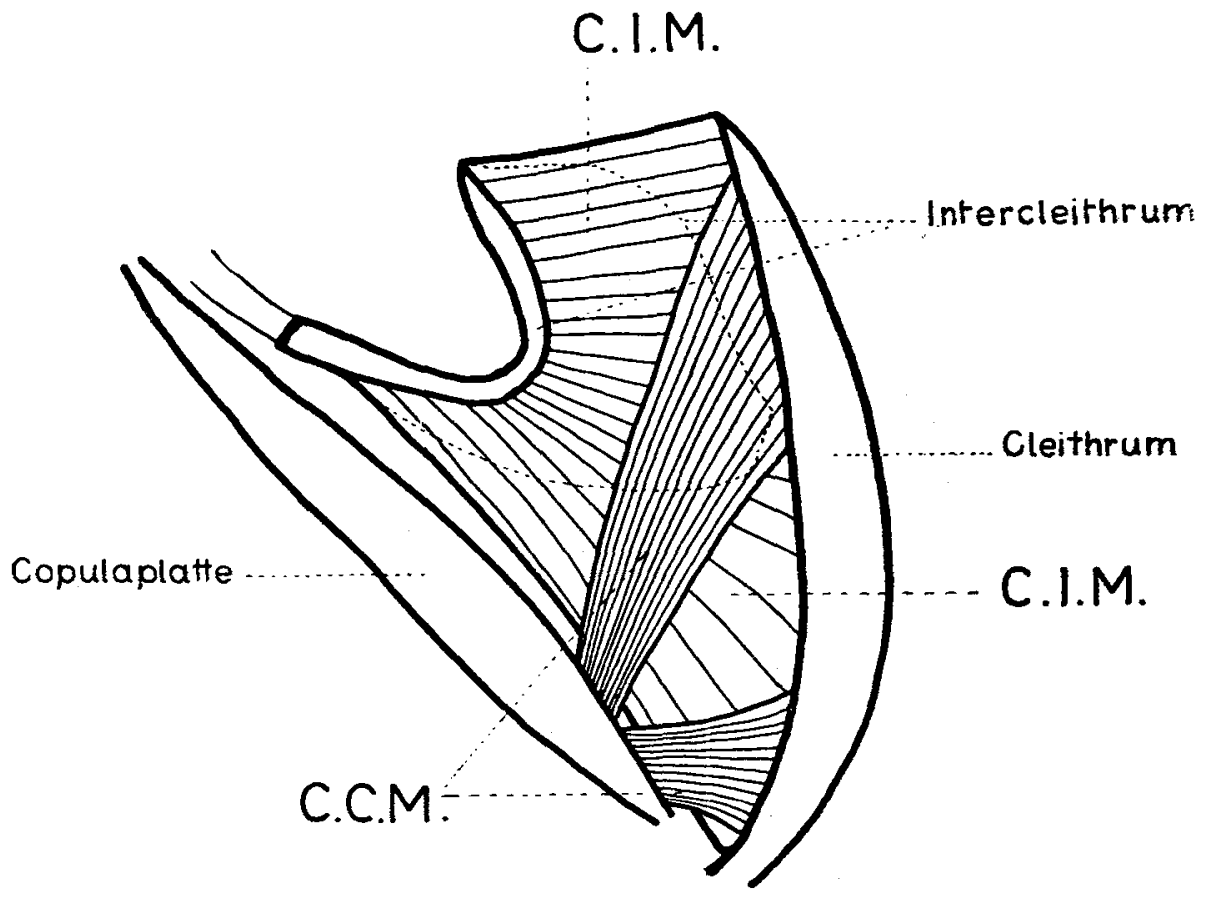

Abb. 11. Schema der Cleithrum-Intercleithrummuskulatur.

Zeichenerklärung: C.I.M. = Cleithrum-Intercleithrum-Muskelgruppe (die der Funktion des Sternohyoideus entspricht). C. C. M. = Muskelbündel, die vom Cleithrum zum kaudalen Ende der Copulaplatte ziehen.

(Die Umrandung des zarten Intercleithrumknochenblatts, das in die Muskelmasse eingelagert ist, gestrichelt.)

Muskelmasse eingelagert, der es als Anheftungsplatte dient. Sein Hinterrand beschreibt etwa einen elliptischen Bogen. Der Vorderrand ist hufeisenförmig eingebuchtet. Scharf heben sich voneinander ab die verdickte Leiste des Vorderrandes und das hintere, zarte Knochenblatt, das die größere Fläche dieses Knochens einnimmt. Es ist in der Region der Polfläche seiner elliptischen Rundung, also an der nach hinten weisenden, schwachen Zuspitzung, in zwei Knochenflügel gespalten. Der verdickte Vorderrand ist nach beiden Seiten umgeschlagen und bietet so Ansatzleisten für eine Lage derber Muskelbündel.

Von den beiden nach vorn gerichteten Vorsprüngen des hufeisenförmigen Gebildes ist der ventrale Vorsprung abgerundet. Er markiert die Stelle, in welche der Keil des 
vorderen Rumpfabschnitts ausläuft. Der dorsale Vorsprung, unter der Copulaplatte gelegen, läuft in eine Spitze aus. Von ihr aus zieht ein Sehnenbündel nach vorn, das an den Knochen des Zungenbeinbogens unter dem Zungenhügel inseriert. An den im morphologischen Sinn dorsalen Rand des Knochens schließt sich eine Haut an, die zwischen Intercleithrum und Copulaplatte ausgespannt ist. In ihr verlaufen feine Muskeln und Sehnen, die das Intercleithrum mit der Copulaplatte verbindet. Die Hauptmuskeln der Schultergürtelregion ziehen vom Intercleithrum zu den beiden Schultergürtelknochen, den Cleithra. Eine obere Muskelschicht an den Leisten des umgeschlagenen, vorderen Intercleithrumrandes entspringend, liegt unter einer Haut, die an derselben Leiste befestigt ist. Die Bündel inserieren mit ihren hinteren Enden jederseits an der AuBenkante des Schultergürtelknochens. Besonders in der dorsalen Region sind sie nicht durchlaufend, sondern erscheinen segmentiert. Die vordere Bündelreihe inseriert mit ihren hinteren Enden, die hintere Bündelreihe mit ihren vorderen Enden an der derben Haut, unter der sie entlanglaufen. Die Segmentierung setzt sich anch in der Ventralregion fort, dort, wo die einzelnen Bündel durchlaufen. Hier sind in einer Unterbrechungszone die Muskelbündel etwas schmäler und sehniger geworden. Bei manchen Tieren ist die Segmentierung in der Ventralregion aber verwischt.

Unter dieser oberen Muskelschicht entspringen an der breiten Fläche des Intercleithrumblatts weitere, tiefer gelegene Muskeln, die ebenfalls zu der vorderen Fläche der beiden Schultergürtelknochen führen. Besonders kräftig sind die Fasern entwickelt, die an den beiden durch Leisten versteiften Flïgeln des Knochenblatts entspringen.

Den Bewegungsmechanismus dieser Apparatur muß man sich wohl folgendermaßen vorstellen: Eine Kontraktion der beschriebenen Muskulatur zieht die in die Muskeln eingelagerte Knochenplatte des Intercleithrum, besonders aber ihre etwas freier bewegliche dorsale Spitze, ein wenig nach hinten gegen den Schultergürtel. Hierdurch zieht aber die Spitze, die ja mit dem Zungenbeinbogen durch ein Sehnenband verbunden ist, diesen ebenfalls nach hinten, wodurch er sich, seiner Bewegungsweise entsprechend, gleichzeitig ventralwärts weit auswinkelt, das Maul öffnet und die Mundhöhle erweitert (s. S. 251 u. 252). Man kann diese Bewegung am toten Tier nachahmen, ganz geringe Verlagerungen der Intercleithrumspitze haben bereits erhebliche Ausschläge zur Folge.

Ueber die beschriebene Intercleithrummuskulatur sind auf jeder Schultergürtelseite zwei Muskelbänder gelagert (s. Abb. 11), die vom äußeren Rand des Cleithrum zur hinteren Region der Copulaplatte führen. Sie verlagern die hintere Copulaplatte und die Kiemenbögen ventralwärts, wobei sich letztere korbartig auseinander biegen und die seitlichen Kiemenbögen erweitern.

Bei der Operation mußte zunächst die Sehne durchschnitten werden, die das Intercleithrum mit dern Zungenbeinbogen verbindet, weil hierdurch die Wirkung der Intercleithrummuskulatur vollständig ausgeschaltet wird. Es schien mir günstig, auch ein Stück der Haut zu durchschneiden, die zwischen Copulaplatte und Intercleithrum ausgespannt ist, weil in sie eingelagert ebenfalls Sehnen und feine Muskelbündel zur Copulaplatte ziehen. Bis in die hintere Region der Copulaplatte konnte ich den Schnitt allerdings nicht führen, da ich das Tier sonst zu stark verletzt hätte. ${ }^{1}$ ) Die Arbeit einiger kleiner Muskelbündel konnte daher wohl nicht ausgeschaltet werden. Ihre Leistung wird aber im Vergleich zu der kräftigen Intercleithrummuskulatur kaum ins Gewicht fallen. Um auch die Muskelbänder, die die hintere Region der Copulaplatte senken, auszuschalten, führte ich je einen Schnitt auf jeder Seite an der Gleitfläche des Schultergürtels entlang. Hiermit war die gesamte Schultergürtelmuskulatur lahm gelegt.

Die zweite Muskelgruppe, deren Bedeutung ich an der Apparatur nachprüfen wollte, war die Muskulatur der Branchiostegalmembran. Ein genaues Studium gerade ihrer Wirkung erschien in diesem Falle besonders dringend, gehören doch die Plattfische, wie viele bodenlebende Teleosteer, zu den „Branchiostegalmembran-Atmern“.

BORCEA, der hier schon einmal zitiert wurde, hat für Trachinus, also für einen Fisch, der allein mit der Brachiostegalmembran atmet, ein Bild dieser Muskeln gegeben. Dies ist von BABÁK (1931) in seine Monographie über "Mechanik und Innervation der Atmung" in WINTERSTEIN's Handbuch aufgenommen worden. Die Verhältnisse bei den Plattfischen weichen aber in wesentlichen Punkten von Trachinus ab. Die Anatomie dieser Muskeln soll daher etwas eingehender beschrieben werden (s. Abb. 12). Sie liegen auf

1) Die Kiemenhöhlen wurden durch die Operationsschnitte gegen das Außenmedium nicht geöffnet. Der ventrale Bezirk der Branchiostegalmembran konnte sich weiterhin der Cleithrumgleitfläche eng anlegen und den Kiemenspalt in der Inspirationsphase abschließen. 
der Innenseite des Kiemendeckels. Je zwei Gruppen fungieren als Inspíratoren und Exspiratoren. Als Inspiratoren müssen einmal alle diejenigen Muskelbänder angesehen werden, die an dem verwachsenen 1. Branchiostegalstrahlenpaar entspringen. In breiten Bändern führen sie in der unteren Region zum letzten, 7. Branchiostegalstrahl. Ueber dieser Zone führen schmälere Bänder, und auch diese in geringerer Zahl, zu den mittleren Branchiostegalstrahlen. Die Muskeln des 2. Strahls inserieren nicht mehr an der Knochenleiste des verwachsenen 1. Paares, sondern frei in der Kiemendeckelhaut der ventralen Verwachsungszone. Da der Knochenkiel in der ventralen Linie fixiert ist, müssen alle diese Muskelbänder die Branchiostegalstrahlen unter dem Kiemendeckel hervorziehen und sie ausspannen, eine typische Inspirationsbewegung ausführen.

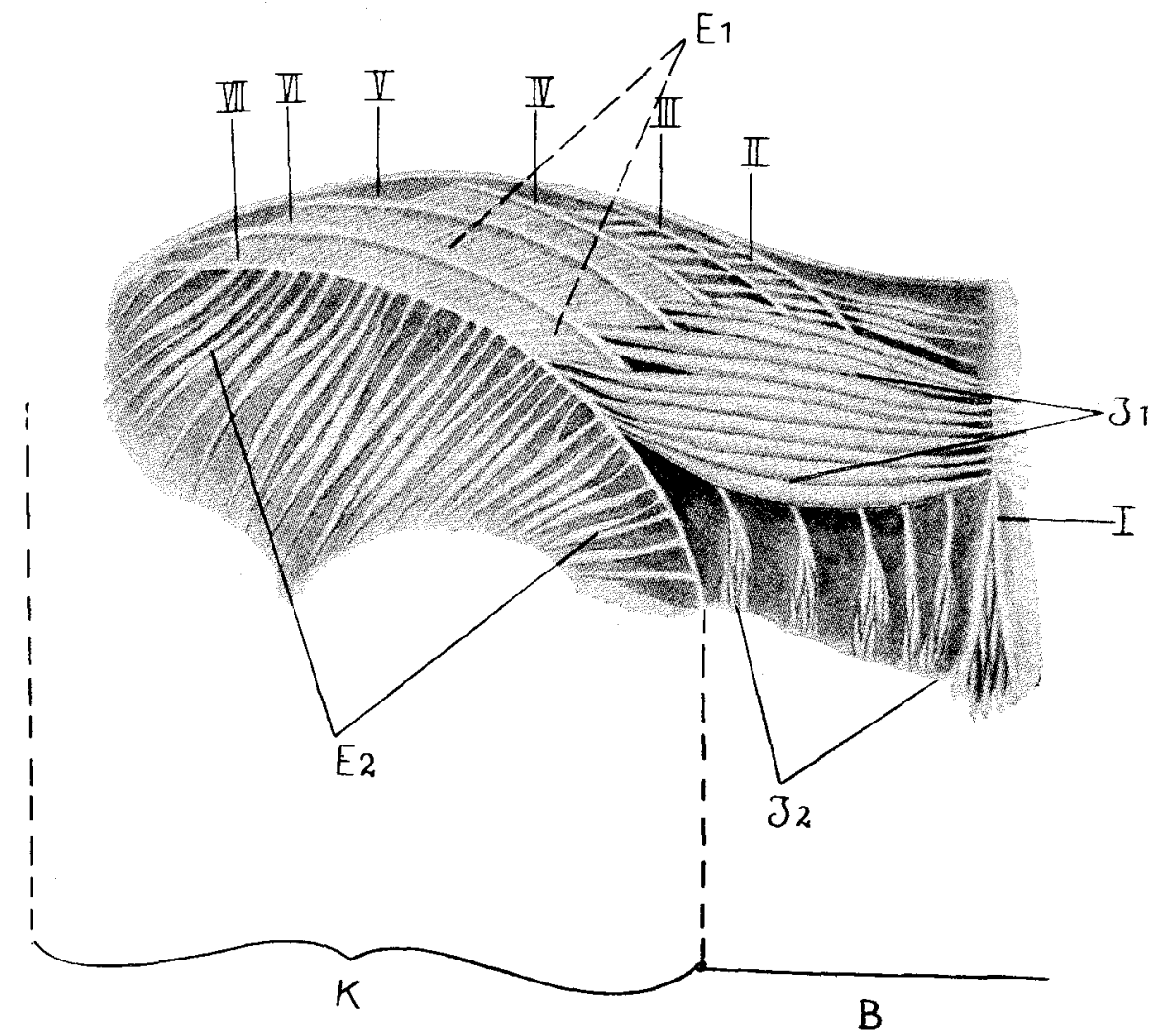

Abb. 12. Die Muskeln der Branchiostegalmembran (Scholle).

Kiemendeckel $=\mathrm{K}$ und Branchiostegalmembran $=\mathrm{B}$ einer Seite, ron innen gesehen.

I: 1. verwachsener Branchiostegalstrahl.

II-VII : 2.-7. Branchiostegalstrahl.

$J 1=$ Inspiratoren der Branchiostegalmembran („Bändermuskeln“).

$\mathrm{J} 2=$ Inspiratoren an den Basen der Branchiostegalstrahlen (Ansatzstellen am Hyale abgeschnitten). $\mathrm{E} 1$ = Exspiratoren der Branchiostegalstrahleu.

E2 2 Exspiratoren des inneren Kiemendeckels (am 7. Strahl inserierend).

(Die Abbildung wurde mir freundlicherweise von Frl. Dr. A. STIER gezeichnet.)

Eine zweite Gruppe dieser Inspiratoren befindet sich an den Basen der Branchiostegalstrahlen. Es sind dies recht kräftige Muskelbündel, die an der Basis jedes Strahls zum äußeren Rand und zur Außenfläche des Hyale ziehen. Nur dem 7. Branchiostegalstrahl, der den Hauptanteil der Muskelbänder bekommen hat, fehlt dieser Muskel. Sie spreizen die Strahlen fächerförmig auseinander. BORCEA unterscheidet beim Trachinus dieselben Muskelgruppen, er nennt die erste Muskelgruppe Musculi extensores distales, die zweite Gruppe M. extensores proximales.

Als Exspiratoren fungieren einmal die kleinen Muskelbündel, die jeweils hinter den durchlaufenden Muskelbändern der Inspiratoren beginnen und zwischen je zwei Branchiostegalstrahlen ausgespannt sind. Sie nähern die Strahlen einander, falten die Membran zusammen, führen also Exspirationsbewegungen aus. Es gibt auch Fasern, die nicht 
zwischen zwei benachbarten Strahlen ausgespannt sind, sondern über einen Strahl hinweglaufen und erst am nächstfolgenden inserieren. Es gibt hierin individuelle Unterschiede. Aber unter die Muskelbänder der Inspiratoren setzen sich diese Exspiratoren nicht fort.

Die zweite Gruppe der Exspirationsmuskeln heftet am Außenrand des 7. Branchiostegalstrahls an und bildet über dem inneren, knöchernen Kiemendeckel ein breites Muskelfeld. Die freien Enden der einzelnen Fasern inserieren an der inneren Haut des knöchernen Kiemendeckels. Sie ziehen den 7. Strahl und mit ihm die zusammengefaltete Membran unter den Kiemendeckel zurück.

Von BoRcEa sind die beiden Muskelgruppen nicht unterschieden; er nennt sie musculi levatores der Branchiostegalstrahien. Es scheint mir, daß Inspiratoren und Exspiratoren, die sich zwischen den Kiemenhautspalten unter sich bzw. dem 7. Strahl und der Innenfläche des Operculum ausspannen, den musculi hyohyoidei superiores VETTER's (1878) entsprechen. Sie werden von ihm als Exspiratoren angesprochen. Für den Plattfisch wäre also hier eine Arbeitsteilung eingetreten. Die Bändermuskeln der Strahlen können eben nur deswegen die Membran ausspannen, weil das erste Strahlenpaar, an dem sie inserieren, verwachsen ist. Die musculi hyohyoidei inferiores VETTER's entsprechen offensichtlich den Muskeln der Strahlenbasen, da sie ja, ebenso wie in VeTTER's Darstellung, am Ceratohyale inserieren. Sie werden von VETTER ebenso wie hier als Inspiratoren aufgefaßt.

Wie man bemerken wird, fällt dem 7. Strahl die Führung bei der Branchiostegalmembran-Atmung zu. Er hat den größten Anteil an der Hauptinspirationsmuskulatur, den Bändermuskeln, er besitzt aber auch eine eigene Exspirationsmuskulatur. Vor- und Zurückweichen der Membran wird hauptsächlich von ihm geleistet.

Die Operation betraf, wie in allen Operationsversuchen, wieder hauptsächlich die Inspirationsmuskulatur. In einer Versuchsgruppe wurden die Bändermuskeln durchschnitten, in der Weise, daß ich die Schere in die Kiemenhöhlen einführte und zwischen den einzeınen Branchiostegalstrahlen entlang schnitt, so tief, bis die Spitze der Schere unter der Oberhaut hindurchschimmerte. Natürlich werden hierbei auch immer einige der zwischen je zwei Branchiostegalstrahlen ausgespannten Exspiratoren betroffen. Nach Versuchsende und Tötung des Tieres konnte ich mich davon überzeugen, ob tatsächlich alle Muskelbänder durchschnitten waren. Nur in diesem Falle wurde der Versuch für die Auswertung verwendet.

Nach diesen geschilderten Operationen waren die Muskeln der Strahlenbasen noch in Funktion. In einer anderen Versuchsgruppe wurden sie auch durchschnitten, ebenfalls von der Kiemenhöhle aus, indem ich den Schnitt am Hyale und vorsichtig um die Kiemenhautstrahlen entlangführte. Hierdurch waren dann alle Inspiratoren ausgeschaltet.

Schließlich wurden auch die Muskeln des Kiemendeckels durchschnitten; der Verlauf dieser Muskeln wurde ja schon im anatomischen Teil (Seite 249) besprochen.

Es muß erwähnt werden, daß die Operationen bei Betäubung der Tiere mit Aether ausgeführt wurden.

\section{b) Saugleistung nach Durchschneidung verschiedener Muskeln.}

Ich möchte bei der Besprechung der Versuchsergebnisse mit den Experimenten beginnen, für welche die Muskeln der Branchiostegalmembran durchschnitten wurden. Das Zahlenmaterial dieser Versuche ist in Tabelle 4 zusammengefaßt. Zunächst zeigen die Versuche, bei denen lediglich die Bändermuskeln durchschnitten waren, daß kein Tier seine normale Leistung aufrecht erhalten konnte. Ebensowenig wurde allerdings ein Aufhalten der Luftblasenwanderung beobachtet. Die Saugarbeit ist lediglich verringert worden. Der Bewegungsmodus zeigt ebenso deutlich, welchen Einfluß der Ausfall der Membranmuskulatur auf die Atmung hat. Die Membran konnte nicht mehr über den Schultergürtel ausgespannt werden. Im 5. Versuch ist eine leichte Membranausspannung vermerkt. Diese Bewegung konnte aber die Arbeit der Bänder nicht ersetzen. Das Tier hat hauptsächlich mit dem Operculum und mit den Kiemenbögen geatmet, es hat aber auch den Palatinbogen in die Bewegungen einbezogen. Dem entsprechend sah man die Luftblase mehr oder weniger häufig in der Exspiration wieder zurückwandern. Ich füge als Beispiel dafür eine Atemreihe an, normal, das andere Mal nach Operation, an der diese Beobachtung deutlich gezeigt wird. 
Zeichen: +: Luftblase wandert in der Exspiration nicht zurück.

-: Luftblase wandert in der Exspiration ein kleines Stück zurück.

$=$ : Luftblase wandert in der Exspiration stark zurück.

1. Normal

$+++++++++++++++++++\frac{1}{1}-+++++t+$

2. Bändermuskeln durchschnitten

$++\cdots++++==-+\ldots-\cdots+-+++=$

Tabelle 4.

Saugleistung von Schollen an der Glasschlange, normal und nach Durchschneidung der Muskelbänder (s. Text) der Branchiostegalmembran.

\begin{tabular}{|c|c|c|c|c|c|}
\hline \multirow{2}{*}{$\begin{array}{l}\text { Tier } \\
\text { cm Länge }\end{array}$} & \multicolumn{2}{|c|}{ Normal } & \multicolumn{2}{|c|}{$\begin{array}{l}\text { Muskelbänder durch- } \\
\text { schnitten }\end{array}$} & \multirow{2}{*}{ Bemerkungen zu den Operationsversuchen } \\
\hline & $\begin{array}{r}\text { saugt cem } \\
\text { je Minute }\end{array}$ & $\begin{array}{l}\text { Wasser } \\
\text { je Atemzug }\end{array}$ & $\begin{array}{r}\text { saugt cer } \\
\text { je Minute }\end{array}$ & $\begin{array}{l}\text { n Wasser } \\
\text { je Atemzug }\end{array}$ & \\
\hline 23 & 13,6 & 0,97 & 3,0 & 0,27 & $\begin{array}{l}\text { Kiemendeckel, Palatinbogen arbeiten, Luft- } \\
\text { blase wandert in der Exspiration häufig zuríck. }\end{array}$ \\
\hline 20 & 8,5 & 0,50 & 6,4 & 0,32 & $\begin{array}{l}\text { Hauptsächlich Kiemendeckelatmung (und } \\
\text { Kiemenbögen?) Luftblase wandert gelegent- } \\
\text { lich zurück. }\end{array}$ \\
\hline 22 & 4,8 & 0,27 & 1,9 & 0,16 & Luftblase wandert gelegentlich zurück. \\
\hline 23 & 5,1 & 0,39 & 2,2 & 0,28 & Luftblase wandert gelegentlich zurück. \\
\hline 22 & 7,4 & 0,44 & 3,9 & 0,15 & $\begin{array}{l}\text { Kiemendeckelatmung und geringe Membran- } \\
\text { ausspannung. Luftblase wandert gelegentlich } \\
\text { zurück. }\end{array}$ \\
\hline 22 & 5,3 & 0,36 & 3,1 & 0,15 & Luftblase wandert gelegentlich zurück. \\
\hline littel & 7,5 & 0,49 & 3,4 & 0,22 & \\
\hline
\end{tabular}

Wurden nun außer den Bändermuskeln auch die Muskeln der Strahlenbasen, also die M. extensores proximales (Tabelle 5) durchschnitten, so zeigte sich, das Letztere doch auch die Membran müssen ausspannen und Saugbewegungen ausführen können. Denn erst jetzt konnte in mehreren Fällen ein vollständiger Stillstand der Luftblasenwanderung beobachtet werden. Das betreffende Tier konnte dann kein Wasser mehr durch die Glasschlange saugen. Offenbar haben die Fische auch ihre Kiemenspalten und die Branchiostegalmembran nicht mehr fest verschließen können, weil ihrer Membran auch der geringste Spannungsgrad fehlte. Denn diejenigen Tiere, die trotz Durchschneidung sämtlicher Membraninspiratoren haben Saugarbeit leisten können, haben zur Verschließ̧ung

Tabelle 5 .

Saugleistung von Schollen an der Glasschlange, normal und nach Durchschneidung aller Inspiratoren der Branchiostegalmembran.

\begin{tabular}{|c|c|c|c|c|c|}
\hline \multirow{2}{*}{$\begin{array}{c}\text { Tier } \\
\text { cm Länge }\end{array}$} & \multicolumn{2}{|c|}{ Normal } & \multicolumn{2}{|c|}{$\begin{array}{l}\text { Inspiratoreu durch- } \\
\text { schnitten }\end{array}$} & \multirow{2}{*}{$\begin{array}{c}\text { Bemerkungen } \\
\text { zu den Operationsversuchen }\end{array}$} \\
\hline & $\begin{array}{l}\text { saugt ecn } \\
\text { je Minute }\end{array}$ & $\begin{array}{l}\text { n Wasser } \\
\text { je Atemzug }\end{array}$ & $\begin{array}{l}\text { saugt ccn } \\
\text { je Minute }\end{array}$ & $\begin{array}{l}\text { Wasser } \\
\text { je Atemzug }\end{array}$ & \\
\hline 21 & 4,6 & 0,19 & - & - & Keine Wanderung der Luftblase \\
\hline 22 & 3,8 & 0,20 & 1,2 & - & Kiemendeckel, Kiemenbögenarbeit \\
\hline 26 & 7,0 & 0,63 & 3,2 & 0,06 & Kiemendeckel und Kiemenbögen in Bewegung \\
\hline 22 & 6,7 & 0.48 & - & 0,21 & $\begin{array}{l}\text { Geringe Wanderung der Luftblase dann Still- } \\
\text { stand }\end{array}$ \\
\hline 23 & 9,6 & 0,40 & - & - & Keine Wanderung der Luftblase \\
\hline Mittel & 6,3 & 0,38 & 0,9 & 0,05 & \\
\hline
\end{tabular}


des Kiemenspalts auffallend stark den Rand des knöchernen Kiemendeckels gegen den Schultergürtel gepreft. Diese Haltung konnte gelegentlich auch bei der Atmung nicht operierter Tiere an der Glasschlange beobachtet werden. Fische, die keine Saugarbeit haben leisten können, führten regelmäßige Atemzüge aus, durch welche das Wasser in der Inspiration von rückwärts durch die Kiemenspalten in die seitlichen Kiemenhöhlen eingesaugt wurde, in der Exspiration auf demselben Wege wieder ausgestoßen wurde.

Einige Tiere konnten aber, wie gesagt, trotz Durchschneidung sämtlicher Membraninspiratoren noch geringe Saugarbeit leisten. Außer dem erwähnten Verschluß der Kiemenspalten durch den Kiemendeckel, besonders durch den Rand des. Präoperculum, war die starke Bewegung des Zungenbeinbogens und der Kiemenbögen auffallend. Sie war es, die hauptsächlich den Saugeffekt hervorrief. Das Operculum spielte nur noch schwach mit, eine starke Abduktion hätte ja den Kiemenspalt geöffnet.

Die Rolle, die die Kiemendeckelbewegungen im Atmungsakt spielen, sollten Durchschneidungen der Operculummuskeln klarstellen. Durchschneidungen der Operculummuskeln allein ergaben nun keine Aenderungen der Saugleistung. Das Tier besitzt zu viel verschiedene Glieder, die die Arbeit des Operculum vollständig ersetzen können. Interessant waren aber Durchschneidungen der Membranmuskeln und der Operculummuskeln gleichzeitig (Tabelle 6). In zwei Fällen waren keine Aenderungen der Saugleistung eingetreten, in zwei anderen Fällen trat Stillstand der Blasenwanderung ein. Die Bewegungsmodi zeigen in allen vier Fällen starke Bewegungen von Kiemenbögen und Zungenbeinbogen; gelegentlich beobachtete ich auch Abduktion des Palatinbogens. Bei Fehlleistungen konnte ich beobachten, daß der Kiemendeckel in der Inspiration klaffte. Es ist danach gut denkbar, daß bei der Operation durch einen mehr oder weniger tiefen Schnitt der musculus adductor operculi entweder in Mitleidenschaft gezogen wurde oder verschont blieb und daß sich aus diesen operativen Unterschieden Unterschiede in der Leistung ergaben. Aber es ist auch nicht ausgeschlossen, daß individuelle Unterschiede vorliegen. Einige Tiere hätten dann die richtige Haltung des Kiemendeckels „entdeckt“, andere nicht. Es ist ja schon hervorgehoben worden, welche individuellen Unterschiede. bei unverletzten Tieren hierin bestehen.

\section{Tabelle 6.}

Saugleistung von Schollen an der Glasschlange, normal und nach Durchschneidung der Bändermuskeln der Branchiostegalmembran allein und gemeinsam mit den Muskeln des Kiemendeckels.

\begin{tabular}{|c|c|c|c|c|c|c|c|}
\hline \multirow{2}{*}{$\begin{array}{l}\text { Tier } \\
\text { cm Länge }\end{array}$} & \multicolumn{2}{|c|}{ Normal } & \multicolumn{2}{|c|}{$\begin{array}{l}\text { Bändermuskeln } \\
\text { durchschnitten }\end{array}$} & \multicolumn{2}{|c|}{$\begin{array}{c}\text { Bändermuskeln und } \\
\text { Kiemendeckelmuskeln } \\
\text { durchsehnitter }\end{array} \mid$} & \multirow{2}{*}{$\begin{array}{c}\text { Bemerkungen } \\
\text { zu der } 3 . \text { Versuchsreihe }\end{array}$} \\
\hline & \multicolumn{2}{|c|}{$\begin{array}{l}\text { saugt ccm Wasser } \\
\text { je Minute } \\
\end{array}$} & \multicolumn{2}{|c|}{$\begin{array}{l}\text { saugt ccm Wasser } \\
\text { je Minute lje Atemzug }\end{array}$} & \multicolumn{2}{|c|}{$\begin{array}{l}\text { saugt ccm Wasser } \\
\text { je Minute } \\
\end{array}$} & \\
\hline 23 & 13,6 & 0,97 & 3,0 & 0,27 & - & - & Kiemendeckel klaffen in der Inspiration \\
\hline 26 & 7,0 & 0,63 & 3,2 & 0,21 & 3,5 & 0,29 & $\begin{array}{l}\text { Zungenbeinbogen, Kiemenbögen in Be- } \\
\text { wegung }\end{array}$ \\
\hline 22 & 4,8 & 0,27 & 1,9 & 0,16 & 1,6 & 0,12 & $\begin{array}{l}\text { Zungenbeinbogen, Kiemenbögen in Be- } \\
\text { wegung }\end{array}$ \\
\hline 20 & 8,8 & 0,30 & 4,3 & 0,13 & - & - & Kiemendeckel klaffen \\
\hline
\end{tabular}

Die bisher besprochenen Ergebnisse zeigen also deutlich, daß den Membranmuskeln der Plattfische eine Hauptaufgabe bei der Saugleistung zukommt. Die beiden Gruppen der Inspiratoren teilen sich in diese Aufgabe. Ich möchte das so ausdrücken, daß die Bändermuskeln die aktive Arbeit, nämlich die Erweiterung der seitlichen Kiemenhöhle, das Ansaugen des Wassers zu leisten haben. Während den Muskeln der Strahlenbasen ein mehr statisches Moment zukommt, die Membran gespreizt, den Hohlraum gegen den äußeren Wasserdruck aufgewölbt und erweitert zu halten und doch zugleich den Kiemenspalt fest zu verschließen. Die Arbeit der Operculummuskeln tritt für die „Membranatmer $^{\star}$ etwas in den Hintergrund, wenn sie die Tätigkeit der Membran auch unterstützen, unter Umständen sogar ersetzen können. Aber die Versuche haben doch gleichzeitig gezeigt, daß dem Zungenbeinbogen und den Kiemenbögen ein sehr wirksamer Anteil an 
der Gesamtleistung der Saugarbeit zukommt. Ihre Bedeutung sollte durch Ausschaltung der Schultergürtelmuskulatur ermittelt werden. Die Tabelle 7 zeigt ein sehr interessantes Ergebnis. Die Fische haben nach der Operation zunächst ebenso stark geatmet wie normal, in mehreren Fällen sogar stärkere Saugarbeit geleistet. In den meisten Fällen wurde hierbei eine sehr starke Membranatmung beobachtet. Unterstützt wurde diese Tätigkeit der Membran aber immer noch von den Kiemenbögen. Für ihre Bewegungen können nur die Muskeln verantwortlich gemacht werden, die den Kiemenbögen selbst

\section{Tabelle 7 .}

Saugleistung von Schollen an der Glasschlange, normal und nach Durchschneidung der Intercleithrummuskulatur.

\begin{tabular}{|c|c|c|c|c|c|}
\hline \multirow{2}{*}{$\begin{array}{c}\text { Tier } \\
\text { cm Länge }\end{array}$} & \multicolumn{2}{|c|}{ Normal } & \multicolumn{2}{|c|}{$\begin{array}{l}\text { Intercleithrummusku- } \\
\text { latur durchschnitten }\end{array}$} & \multirow{2}{*}{$\begin{array}{c}\text { Bemerkungen } \\
\text { zu den Operationsversuchen }\end{array}$} \\
\hline & $\begin{array}{l}\text { saugt cen } \\
\text { je Minute }\end{array}$ & $\begin{array}{l}\text { n Wasser } \\
\text { je Atemzug }\end{array}$ & $\begin{array}{l}\text { saugt } \mathrm{ccm} \\
\text { je Minute }\end{array}$ & $\begin{array}{l}\text { Wasser }{ }^{1} \text { ) } \\
\text { je Atemzug }\end{array}$ & \\
\hline 24 & 3,7 & 0,19 & 5,7 & 0,29 & $\begin{array}{l}\text { Bei allen Versuchen Membranatmung mit } \\
\text { Unterstützuug der Kiemenbögen. Saugt Luft- } \\
\text { blase bis zu Ende }\end{array}$ \\
\hline 21 & 7,0 & 0,33 & 9,3 & 0,46 & $\begin{array}{l}\text { Saugt Luftblase bis dreiviertel der Glas- } \\
\text { schlange, dann Stillstand }\end{array}$ \\
\hline 21 & - & - & 9,2 & 0,31 & Saugt Luftblase bis zu Ende \\
\hline 21 & 6,4 & 0,27 & 4,3 & 0,16 & $\begin{array}{l}\text { Saugt Luftblase bis } 1 / 4 \text { der Glasschlange, } \\
\text { dann Stillstand }\end{array}$ \\
\hline 22 & 6,4 & 0,29 & 10,2 & 0,60 & $\begin{array}{l}\text { Saugt Luftblase bis } 1 / 4 \text { der Glasschlange, } \\
\text { dann Stillstand }\end{array}$ \\
\hline 20 & 8,1 & 0,62 & 8,2 & 0,32 & Saugt Luftblase bis zu Ende \\
\hline$\overline{\text { Mittel }}$ & 6,3 & 0,34 & 7,8 & 0,36 & \\
\hline
\end{tabular}

eigen sind: Die Levatoren der Kiemenbögen und ihre Antagonisten, die Musculi interarcuales (s. Seite 249). Membranmuskeln und die Muskelgruppen der Kiemenbögen vermögen also allein sehr gute, ja sogar forcierte Saugarbeit zu leisten. Aber diese Leistung kann nur kurze Zeit aufrecht erhalten werden. Wenn die Luftblase das erste Drittel oder etwa die Hälfte der Glasschlange durchwandert hatte, trat vielfach eine sehr starke Verlangsamung, schließlich ein Stillstand ein. Das Tier hörte auf, Wasser zu saugen, der Fisch atmete dann regelmäßig in der Weise, daß er Wasser von hinten durch die Kiemenspalten in die Kiemenhöhlen treten ließ. Ich gebe hierfür als Beispiel den Verlauf eines charakteristischen Versuchs.

Das Tier saugte nach Durchschneidung der Schultergürtelmuskulatur, während die Luftblase durchwanderte
die 1. Hälfte
die 2. Hälfte, 1. Teil
die 2. Hälfte, 2. Teil, 10,6
$0,0 \mathrm{ccm}$ Wasser pro Minute.

Die relativ kleinen Muskeln der Kiemenbögen und der Membran ermüden also rasch, wenn sie starke Saugarbeit zu leisten haben und nicht von der kräftigen Schultergürtelmuskulatur unterstützt werden. Aber eine dominierende Rolle spielt diese Muskulatur im Atmungsakt nicht. So können die Operationsversuche den Eindruck, den man bereits nach den anatomischen Verhältnissen des Atmungsapparats bekommen muß3, bestärken. Die Bedeutung des Zusammenspiels und des Aufeinanderabgestimmtseins der einzelnen Glieder liegt nicht darin, daß ein einzelner Muskel alle Glieder des Apparats gleichzeitig in Bewegung setzen soll, vielmehr im Gegenteil davon, daß jedes Glied, jede Muskelgruppe an seinem Platz und in ihrer Weise arbeitet, und daß trotzdem ein Zusammenspiel des Ganzen zustande kommt. Der Kompliziertheit des Baues entspricht eine Kompliziertheit der Funktion.

1) Werte geben die Saugzeiten während der Luftblasenwanderung an. 


\section{B. Versuche mit Dorschen.}

Gilt dies Prinzip aber auch für den Typus des Teleosteerschädels? Der Plattfisch besitzt als Bodenfisch einen spezialisierten Atmungsapparat. Die ausgeprägte Membranatmung ist eine Anpassung an seine Lebensweise. Wie weit wird man die Anschaungen über die Rollen, die die einzelnen Muskeln im Atmungsakt zu spielen haben, z. B. auf den Gadusschädel übertragen dürfen?

Ich bemerkte, daß die Experimente mit Plattfischen durch die ruhige Lebensweise dieser Tiere sehr erleichtert wurden. Dorsche dagegen, die meistens im Becken umherschwimmen und zuglêich viel erregbarer sind als Plattfische, werden dadurch viel stärker unkontrollierbare Schwankungen im Sauerstoffbedarf erleiden. Schwankungen der Frequenz und Intensität ihrer Atembewegungen werden deshalb mit geringerer Sicherheit Auskunft über die blo(3 mechanische Wirkung der Fixierung oder Ausschaltung einer Gliedergruppe geben können. Diese wird von Einflüssen innerer physiologischer Zustände zu stark überlagert.

War es für das Studium des Bauplans des Atmungsapparats vorteilhaft, den Typus des Teleosteerschädels heranzuziehen, wie ihn der Dorsch darstellt, so war es gerade für das Experiment günstiger, einen spezialisierten Typus, den Bodenfisch zu wählen. An ihm ließ sich das Funktionsprinzip bis zu genauen Einzelheiten verfolgen. Wenn ich dieses aber einmal an einem geeigneten Objekt erkannt habe, werde ich mir wohl eher auch über Atmungsbewegungen jener Fische ein Urteil bilden können, die sich einer experimentellen Bedingung nicht so zwanglos unterwerfen und daher nicht immer so eindeutige Ergebnisse liefern. Solche vergleichenden Beobachtungen wurden nun auch am Dorsch ausgeführt; ich bringe das Ergebnis dieser Untersuchungen in Form einiger Zahlenreihen.

Von mehreren Dorschen wurde die Atemfrequenz bei normaler Atmung gezählt. (Temperatur $15^{\circ} \mathrm{C}$ ). Es ergaben sich folgende Durchschnittsfrequenzen je Minute: 44, 45, $49,48,46$.

Nach Abschneidung des äußeren Randes der Branchiostegalmembran wurde die Frequenz erheblich gesteigert. Die Tiere führten in der Minute 67, 66, 57, 76 Atemzïge aus. Einem Tier, das normalerweise $\mathbf{4 5}$ Atemzüge je Minute ausführte, wurden die Muskeln der Branchiostegalınembran durchschnitten. Das Tier steigerte seine Frequenz nach der Operation auf 59 Atemzüge je Minute. Eine Stunde später atmete es 60 mal in der Minute. Drei Stunden später 59 mal. Wenn man die Steigerung am Anfang des Versuchs hätle lediglich auf Erregung zurückführen wollen, so hätte man im Laufe der daraut folgenden Beobachtungen zum mindesten ein Abklingen der Frequenz beobachten müssen. Dies war nicht der Fall. Die Steigerung bedeutet also genau wie bei den Plattfischen Versagen des Saugpumpenmechanismus, stärkere Arbeit der vorderen Mundhöhle als Druckpumpe. Auch der Bewegungsmodus veränderte sich ganz in demselben Sinn. Besonders starke Spreizungen der Palatinbögen, weites Oeffnen, festes Schließen des Unterkiefers wurde beobachtet. Der letzte Versuch, die Durchschneidung der Membranmuskeln zeigt, daß3 diese für den Saugakt auch des Dorsches wichtig sind. Ich beobachtete, daß besonders dje ventrale Auswölbung der Membran unterblieb. Eine andere Versuchsreihe zeigt aber, daß der Saugpumpenmechanismus der seitlichen Kiemenhöhlen für den Dorsch nicht entfernt die Bedeutung hat, wie für den Plattfisch. Man kann die Saugund Druckpumpenarbeit der Mundhöhle beim Dorsch nur verstehen, wenn man die Rolle kennt, die der Zungenhügel bei dieser Atmung spielt. Der Kabeljau besitzt keine Mundklappen. Er schliebt bei normaler, ruhiger Atmung aber trotzdem seinen Mund oft nicht vollständig. Wenn man einem atmenden Fisch etwa durch die Glaswand eines Aquariums in die Mundhöhle sieht, bemerkt man, daß er bei jeder Exspiration den Zungenhügel fest an den Gaumen legt. Ich vermutete, daß der Zungenhügel mit dieser Bewegung das Atemwasser am Zurückströmen zu verhindern, wenn nicht gar wie der Stempel einer Druckpumpe nach hinten drücken soll. Experimente zeigten, daß diese Vermutung richtig war.

Für die folgenden Versuche bog ich mir ein Stück Draht zu einem Dreieck zurecht, das ich in seiner Form und Größe dem geöffneten Dorschmaul eines $30-35 \mathrm{~cm}$ langen Tieres anpaßte. Es konnte liegend ins Maul eingebunden werden. So verhinderte es wohl den vollständigen Mundverschluß - die Kiefern ließen dann zwischen sich einen schmalen Spalt klaffen, durch den Wasser zwischen Mundhöhle und Außenmedium frei kommunizieren konnte - der Zungenhügel konnte aber noch frei spielen und sich dem Gaumen anlegen. Der Draht konnte aber auch a ufgestellt im Maul festgebunden 
werden. In dieser Stellung ließ er das Maul weit klaffen und hinderte gleichzeitig den Zungenbeinbogen, der sich wohl in der Inspiration ventral abbiegen konnte, sich in der Exspiration dem Gaumen anzulegen, weil die gesamte Kehlpartie etwas ventralwärts verlagert war.

Es wurden nun normalen Fischen und Fischen mit liegendem und aufgestelltem Dreieck mit Pipetten Tuschewolken vor das Maul geblasen und mit der Stoppuhr die Zeit gemessen, die vom Passieren des Unterkiefers bis zum Austritt dieser Wolken aus den seitlichen Kiemenhöhlen verstrich. Außerdem wurden die Atemzüge gezählt, die die Tiere unter den jeweiligen Versuchsbedingungen ausführten. Gleich diese Frequenzzahlen zeigten, daß zwischen Plattfisch und Kabeljau Unterschiede bestehen müssen. Die Frequenz veriangsamte sich nach Spreizung der Mundöffnung und Ausschaltung der Mundhöhlenarbeit nämlich nicht. Folgende Frequenzen wurden gezählt.

$\begin{array}{ccc}\text { normal } & \text { Drahtdreieck liegend } & \text { Drahtdreieck aufgestellt. } \\ 60 & & 57 \\ 42 & 52 & 50 \\ 52 & 52 & 57 \\ 59 & 48 & 57 \\ 48 & 51 & 55\end{array}$

Die Fische haben während dieser Versuche etwas schneller geatmet als früher, wahrseheinlich, weil die Wassertemperatur etwas höher lag als bei den vorhergegangenen Versuchen $\left(18-20^{\circ} \mathrm{C}\right.$ gegenüber $\left.15^{\circ} \mathrm{C}\right)$. Eine Verlangsamung der Atemzüge nach Einbindung des Dreiecks ist aber, wie gesagt, nicht eingetreten, ein Zeichen dafür, daß das Tier nicht so extreme Saugpumpenarbeit leisten kann.

An diesen Tieren wurden nun auch die Tuscheversuche vorgenommen. Die Untersuchungen ergaben ein Bild, wie es Tabelle 8 zeigt.

Normalerweise saugt ein etwa $30 \mathrm{~cm}$ langer Dorsch in einer Sekunde oder in 1-2 Sekunden die Tuschewolken durch die Atemhöhlen. Vergleicht man die Frequenz mit den gefundenen Saugzeiten, so kann man feststellen, daß die Tusche in einem Atemzug durch die Hohlräume gesaugt wird, oder - nämlich dann, wenn die Tusche nicht gleich am Anfang der Inspiration den Unterkiefer passiert - erst mit dem darauffolgenden Atemzug wieder ausgestoßen wird. Es ergeben sich in diesem Fall Saugwerte von 1,5 Atemzügen. Wird dem Fisch mun der Mundverschluß verhindert, kann er aber noch den Zungenhügel gegen den Gaumen pressen, verlangsamt sich die Saugzeit nur wenig. Die Tusche wird in 2 Sekunden oder etwa 2 Atemzügen durch die Hohlräume gesaugt. Bei aufgestelltem Dreieck, wenn also der Zungenhügel an seinem Bewegungsspiel verhindert ist, war die Verlangsamung der Saugzeit wesentlich größer. Der Fisch brauchte 3-4 Sekunden oder annähernd 4 Atemperioden zur Durchsaugung der Tuschewolken durch seine Atemhöhlen. Sieht man dem Fisch ins geöffnete Maul, bemerkt man, daß die Tusche nicht gleich in der ersten Inspiration in die Kiemenhöhlen gelangt, daher in der Exspiration wieder zurückgestoßen wird. In der zweiten Atemperiode kann sich das Spiel wiederholen, erst nach einigen Fehlleistungen gelangen die Tuschewolken oft in die seitlichen Kiemenhöhlen, aus denen sie in der nächstfolgenden Exspiration dann durch den Kiemenspalt ausgestoßen werden. Daraus erklären sich die oft recht langen und unterschiedlichen Saugzeiten. Die Beobachtung ließ ferner erkennen, daß die Tuschewolken viel weniger kompakt aus den Kiemenspalten heraustreten als normal oder bei liegendem Dreieck, sodaß man annehmen muß, jeder Atemzug befördere viel weniger frisches Wasser an den Kiemen vorbei als normal. Diese Versuche erweisen also die Bedeutung des Zungenhügels für den Atmungsakt, der das Wasser in der Exspiration nach hinten drücken soll:

Einen Saugmechanismus besitzt der Dorsch aber auch, andernfalls dürfte die Tuschewolke nicht schließlich doch aus den seitlichen Kiemenhöhlen ausgestoßen werden. WокковоілікоғF irrt aber, wenn er meint, daß die Saugarbeit bei der Atmung auch für den normalen Typus des Teleosteerschädels dominiert. Beim Dorsch jedenfalls kann die Pumparbeit ohne Mitwirkung der Mundhöhle nur sehr unvollständig sein. Dies zeigen auch die Endergebnisse der Versuche: Die Tiere zeigten nach 1-2 Stunden Erstickungserscheinungen, wenn sie mit aufgestelltem Dreieck atmen mußten. Die seitlichen Kiemenhöhlen allein können den Kiemen auf die Dauer nicht so viel Atemwasser zuführen, daf der Fisch sein Blut mit Sauerstoff sättigen kann. 
Tabelle 8.

Atemleistung von Dorschen. Atemfrequenz und Passierzeiten von Tuschewolken durch Mund- und Kiemenhöhle, normal, und nach Offenhaltung des Maules durch ein Drahtdreieck.

\begin{tabular}{|c|c|c|c|c|c|c|}
\hline Tier & Frequenz & $\begin{array}{l}\text { Normal } \\
\text { Passierzeit der Tusche } \\
\text { in Sekunden }\end{array}$ & $\begin{array}{r}\text { Drah } \\
\text { Frequenz }\end{array}$ & $\begin{array}{l}\text { Passierzeit der Tusche } \\
\text { in Sekunden }\end{array}$ & $\begin{array}{r}\text { Draht } \\
\text { Frequenz }\end{array}$ & $\begin{array}{l}\text { tdreieck aufgestellt } \\
\begin{array}{l}\text { Passierzeit der Tusche } \\
\text { in Sekunden }\end{array}\end{array}$ \\
\hline $34 \mathrm{~cm}$ & $\begin{array}{l}61 \\
61 \\
57\end{array}$ & $\begin{array}{l}1,0 \\
1,1 \\
1,1 \\
0,9 \\
1,1 \\
1,0\end{array}$ & & & & \\
\hline Mittel & 59 & $\begin{array}{c}1,0 \\
\text { d.h. in } 1,0 \text { Atemzügen }\end{array}$ & & & & \\
\hline $30 \mathrm{~cm}$ & 61 & $\begin{array}{l}2,0 \\
2 \\
1,5 \\
1,2 \\
1,0 \\
1 \\
2\end{array}$ & $\begin{array}{l}53 \\
51 \\
55 \\
53 \\
57\end{array}$ & $\begin{array}{l}2,8 \\
2,9 \\
1,8 \\
2,3 \\
2,0 \\
2,6 \\
2,0\end{array}$ & $\begin{array}{l}50 \\
60\end{array}$ & $\begin{array}{l}3,0 \\
2,5 \\
2,0 \\
3,5 \\
5,5 \\
4,0 \\
3,0 \\
3,5 \\
3,4\end{array}$ \\
\hline Mittel & 61 & $\begin{array}{c}1-2 \\
\text { d. h. in } 1,5 \text { Atemzügen }\end{array}$ & 54 & \begin{tabular}{|c|}
2.3 \\
d. h. in 2,6 Atemzügen
\end{tabular} & etwa 55 & $\begin{array}{c}3,4 \\
\text { d.h. in 3,7 Atemzügen }\end{array}$ \\
\hline $30 \mathrm{~cm}$ & $\begin{array}{l}48 \\
47 \\
48 \\
48 \\
50\end{array}$ & $\begin{array}{l}1,2 \\
1,4 \\
1,6 \\
1,6 \\
1,4 \\
1,1 \\
1,2 \\
1,6\end{array}$ & $\begin{array}{l}50 \\
48 \\
47\end{array}$ & $\begin{array}{l}1,6 \\
2,0 \\
1,6 \\
1,8 \\
2,6 \\
2,1 \\
1,0 \\
1,6\end{array}$ & $\begin{array}{l}57 \\
57 \\
56\end{array}$ & $\begin{array}{l}3,9 \\
4,5 \\
3,6 \\
6,0 ! \\
3,9 \\
5,1 \\
4,1 \\
3,0 \\
3,0 \\
4,0\end{array}$ \\
\hline Mittel & 48 & $\begin{array}{c}1,4 \\
\text { d. h. in } 1,1 \text { Atemzügen }\end{array}$ & 48 & $\begin{array}{c}1,8 \\
\text { d. h. in } 1,3 \text { Atemzügen }\end{array}$ & 57 & $\begin{array}{c}4,1 \\
\text { d. h. in } 4 \text { Atemzügen }\end{array}$ \\
\hline $\begin{array}{l}\text { Gesamt- } \\
\text { mittel }\end{array}$ & & $\begin{array}{l}\text { in } \mathbf{1 , 3} \text { Sekunden } \\
\mathbf{1 , 2} \text { Atemzügen }\end{array}$ & & 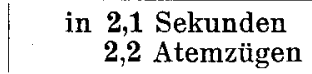 & & $\begin{array}{l}\text { in } \begin{array}{l}3,8 \text { Sekunden } \\
4 \text { Atemzügen }\end{array}\end{array}$ \\
\hline
\end{tabular}

\section{Vergleich der Atemapparate von Dorsch und Scholle.}

Es erhebt sich nun die Frage, ob der Plattfisch, der ja einen so wirksamen Saugmechanismus besitzt, den Zungenhügel zur Unterstützung der Druckpumpenarbeit der Mundhöhle ebenfalls benutzt. Diese Frage ließ sich für die Plattfische an der Apparatur der Glasschlange leicht entscheiden. Ich erwähnte bei der Beschreibung der Versuchsanordnung, daß das in die Mundöffnung um die Lippenknorpel eingebundene Schlauchstück dem Zungenhügel noch freie Beweglichkeit ließ. Wenn ich nun in diese vordere Schlauchmündung ein kurzes Glasrohr einführte, das etwa bis in den inneren Bogen der Kiemenbögen reicht, verhinderte ich den Zungenhügel daran, sich in der Exspiration dem Gaumen anzulegen, während er in ventraler Richtung seine freie Beweglichkeit behielt. Hierdurch ließ sich die Aufgabe des Zungenhügels auch für den Plattfisch erkennen. Es zeigte sich, daß die Saugarbeit nach Einführung des Glasrohrs nachließ. Hierfür seien einige Protokolle gebracht. 


\section{Protokoll 1.}

Scholle $20 \mathrm{~cm}$. Wassertemperatur $17,8^{\circ} \mathrm{C}$.

a) Tier normal vor die Glasschlange gespannt

1. Frequenz: 32 Atemzüge pro Minute.

2. Tier saugt: $\quad 6,1 \mathrm{ccm}$ Wasser pro Minute.

$0,19 \mathrm{ccm}$ Wasser pro Atemzug.

3. Bewegungsmodus: Membranatmung. Operculumbewegung. Unterstützung des Zungenbeinbogens.

Luftblase wandert ohne Rückstoß vorwärts.

b) Glasrohr in die vordere Schlauchöffnung eingeführt.

Der Zungenhügel kann sich nicht mehr dem Gaumen anlegen.

1. Frequenz:

28 Atemzüge pro Minute.

2. Tier saugt:

$5,0 \mathrm{ccm}$ Wasser pro Minute.

$0,18 \mathrm{ccm}$ Wasser pro Atemzug.

3. Bewegungsmodus: Kiemendeckel, Membranatmung, Unterstützung der hinteren

Kiemenregion. Operculum fest auf den Schultergürtel gepreßt.

Die Luftblase erleidet gelegentlich in der Exspiration einen Rückstoß.

$$
\text { Protokoll } 2 .
$$

Scholle $21 \mathrm{~cm}$. Wassertemperatur $18,5^{\circ} \mathrm{C}$.

a) Tier normal vor die Glasschlange gespannt.

1. Frequenz: 18 Atemzüge pro Minute.

2. Tier saugt: $\quad 9,0 \mathrm{ccm}$ Wasser pro Minute.

3. Bewegungsmodus: Memuranatmung.

9,0 ccm Wasser pro Minute.
$0,50 \mathrm{ccm}$ Wasser pro Atemzug.

b) Glasrohr in die vordere Schlauchöffnung eingeführt. Der Zungenhügel kann sich nicht mehr dem Gaumen anlegen.

1. Frequenz:

21 Atemzüge pro Minute.

2. Tier saugt:

2,2 ccm Wasser pro Minute.

$0,10 \mathrm{ccm}$ Wasser pro Atemzug.

3. Bewegungsmodus: Palatinbogenatmung.

Starkes Zurückweichen der Luftblase in der Exspiration.

\section{Protokoll 3.}

Scholle $19 \mathrm{~cm}$. Wassertemperatur $18,5^{\circ} \mathrm{C}$.

a) Tier normal vor die Glasschlange gespannt.

1. Frequenz:

14 Atemzüge pro Minute.

2. Tier saugt:

$11,8 \mathrm{ccm}$ Wasser pro Minute.

$0,84 \mathrm{ccm}$ Wasser pro Atemzug.

3. Bewegungsmodus: Extreme Membranatmung.

Kein Zurückweichen der Luftblase in der Exspiration.

b) Glasrohr in die vordere Schlauchöffnung eingeführt.

Der Zungenhügel kann sich nicht mehr dem Gaumen anlegen.

$$
\text { ( } b^{1} \text { erster Teil }=3 / 4 \text { der Glasschlange.) }
$$

1. Frequenz: 17 Atemzüge pro Minute.

2. Tier saugt: $\quad 7,4$ ccm Wasser pro Minute.

$0,44 \mathrm{ccm}$ Wasser pro Atemzug.

3. Bewegungsmodus: Membranatmung mit Unterstützung des Palatinbogens. Luftblase erleidet mit jeder Exspiration einen kleinen Rückstoß. 


\section{( $b^{2}$ letzter Teil der Glasschlange.)}

1. Frequenz:

15 Atemzüge pro Minute.

2. Tier saugt:

$3,3 \mathrm{ccm}$ Wasser pro Minute.

$0,22 \mathrm{ccm}$ Wasser pro Atemzug.

3. Bewegungsmodus: Starke Palatinbogenbewegung. muskeln.

Ermüdung der Membran-

Starke Rückstöße der Luftblase in der Exspiration.

\section{Protokoll 4.}

Scholle $21 \mathrm{~cm}$. Wassertemperatur $17,2^{\circ} \mathrm{C}$.

a) Tier normal vor die Glasschlange gespannt.

1. Frequenz: 26 Atemzüge pro Minute.

2. Tier saugt: $\quad 5,1 \mathrm{ccm}$ Wasser pro Minute.

$0,20 \mathrm{ccm}$ Wasser pro Atemzug.

3. Bewegungsmodus: Schwache Membranatmung, Kiemenbögen in Bewegung.

b) Glasrohr in die vordere Schlauchöffnung eingeführt. Der Zungenhügel kann sich nicht mehr dem Gaumen anlegen.

Kiemen- und Palatinbogenatmung. Die Luftblase wandert nur dreimal ein kurzes Stück vorwärts. Dabei in der Exspiration mehrfach Rückstöße.

1. Frequenz:

I. Wanderung der Luftblase :

2. Tier saugt:

25 Atemzüge pro Minute.

$3,8 \mathrm{ccm}$ Wasser pro Minute.

$0,15 \mathrm{ccm}$ Wasser pro Atemzug.

1. Frequenz:

II. Wanderung der Luftblase:

2. Tier saugt:

28 Atemzüge pro Minute.

5,1 ccm Wasser pro Minute.

$0,18 \mathrm{ccm}$ Wasser pro Atemzug.

III. Wanderung der Luftblase:

1. Frequenz:

31 Atemzüge pro Minute.

2. Tier saugt:

5,1 cem Wasser pro Minute.

$0,16 \mathrm{ccm}$ Wasser pro Atemzug.

Die Unterschiede zwischen Saugleistungen mit und obne Glasrohr schwanken. In Protokoll 1 nur klein, waren sie in den Versuchen der Protokolle 2 und 3 erheblich größer. Protokoll 4 zeigt einen Versuch, bei dem sich das Nachlassen der Saugkraft in einem häufigen Stillstand der Luftblase bemerkbar machte. In der Periode der Wanderung waren die Leistungen dem "Normal"-fall sehr ähnlich. Die Luftblase wanderte nach Ausschaltung des freien Spieles des Zungenhügels viel häufiger in der Exspiration zurück, ein Zeichen, daß die Zungenbeinbewegung gerade die Exspirationsbewegung, also die Druckkraft, sehr untersiützt. Die Verhältnisse liegen also ähnlich wie beim Dorsch. Aber auch ohne Bewegungen des Zungenhügels konnten die Plattfische noch recht erhebliche Pumparbeit leisten, der Saugmechanismus ihrer seitlichen Kiemenhöhlen ist wirkungsvoller als beim Kabeljau.

Zusammenfassend kann man wohl sagen, daß die beiden Fischtypen, der freie Schwimmer und der Bodenfisch, beide Atmungsmechanismen, die Druckpumpe der Mundhöhle und die Saugpumpen der Kiemenhöhlen zu ihrem Atinungsakt gebrauchen. Das Hauptgewicht liegt aber für die freischwimmende Art vom Dorschtypus auf der Druckpumpenarbeit, für den Bodenfisch auf der Saugarbeit der seitlichen Kiemenhöhlen.

\section{Zusammenfassung.}

1. Es wird der Bauplan des Branchiovisceralskeletts und der Bewegungsmechanismus der Mundkiemenhöhle an Hand des Gadusschädels beschrieben.

2. Bei der Erforschung der Funktion der drei Hohlräume (Mundhöhle und der beiden Kiemenhöhlen) des Branchiovisceralapparats im Atmungsakt haben sich besonders 
BAGLioni und Woskoboinikoff Verdienste erworben. An ihren Hypothesen werden die mutmaßlichen Arbeitsweisen von Mund- und Kiemenhöhle erläutert. Man kann wohl sagen - damit wird an dieser Stelle ein Ergebnis der eigenen Untersuchungen vorweg genommen - daß BAGLIon die Arbeitsweise der Mundhöhle richtig beurteilt hat, während Woskobolnikoff, der die Trennung der Mund- von den Kiemenhöhlen entdeckte, in seinem Schema vorwiegend die Arbeit der Kiemenhöhlen berücksichtigt.

3. Im zweiten Teil, dem Hauptteil der Arbeit, werden die eigenen Experimente besprochen. Atemfrequenz, Bewegungsmodus und Sauerstoffverbrauch wurde an Plattfischen (Scholle und Flunder) gemessen, einmal normal, zweitens nach Abschneidung des äußeren Randes der Branchiostegalmembran (Außer-Funktionsetzung der seitlichen Kiemenhöhlen), drittens nach Einbindung eines offenen Gummirohrs in die Mundöffnung (Außer-Funktionsetzung der Mundhöhle).

Der Sauerstoffverbrauch änderte sich nicht, dagegen taten dies Frequenz und Bewegungsmodus. Die Veränderungen, charakteristisch verschieden, je nachdem, welche Hohlräume ausgeschaltet waren, wurden aus den verschiedenen Arbeitsweisen der Hohlräume erklärt. Es funktioniert darnach die Mundhöhle als Druckpumpe. Sie leistet in der Exspiration ihre Hauptarbeit. Die Kiemenhöhlen funktionieren als Saugpumpen, die in der Inspiration ihre Hauptarbeit leisten.

4. Die Saugpumpenarbeit der Kiemenhöhlen wurde direkt nachgewiesen, indem der Fisch aus einem neben dem Aquarium stehenden Zylinder Wasser gegen das hydrostatische Gefälle saugen mußte.

5. Um die Menge des mit jedem Atemzug durch die Kiemenhöhlen gesaugten Wassers festzustellen, wurde der Fisch vor ein mehrfach gewundenes Glasrohr gespannt, durch das er sein Atemwasser saugen mußte. An der Wanderung einer in das offene Ende eines Glasrohrs eingeblasenen Luftblase konnte die Menge des mit jedem Atemzug durchsaugten Wassers gemessen werden. $20-23 \mathrm{~cm}$ lange Schollen saugten im Mittel $0,4 \mathrm{ccm}$ Wasser in jedem Atemzug. Die Schwankungen waren groß.

6. Durchschneidungen der Atemmuskeln sollten erweisen, welche Rolle die verschiedenen Muskelgruppen der Branchiovisceralapparatur für den Atmungsakt spielen. Am wichtigsten sind für die Plattfische die Muskeln der Branchiostegalmembran, von denen auch eine Abbildung gegeben wird. Nur unterstützend wirken die Muskeln des Operculum. Die komplizierte Muskelgruppe des Schultergürtels, die dem Musculus sternohyoideus entspricht (in einer schematischen Abbildung gezeigt), erwies sich nur für kurze Zeit im Atmungsakt bei stärkerer Saugleistung als entbehrlich. Durchschneidungen dieser Muskeln hatten nämlich eine schnelle Ermüdung der übrigen Atemmuskulatur zur Folge.

Aus diesen Beobachtungen wurde geschlossen, daß beim normalen Atmungsakt die verschiedenen Muskelgruppen zusammenspielen. Dem komplizierten Bau des Organs entspricht eine ähnlich komplizierte Funktion.

7. Vergleichende Untersuchungen wurden zwischen Dorsch und Plattfisch angestellt. Auch am Dorsch konnte ähnlich wie beim Plattfisch die Saugpumpenarbeit der seitlichen Kiemenhöhlen nachgewiesen werden. Im Gegensatz zum Plattfisch ist seine Atmung nur sehr unvollständig, wenn die Druckpumpenarbeit der Mundhöhle ausfällt. In diesem Zusammenhang wurde festgestellt, daß der Zungenhügel der Druckpumpenarbeit eine wichtige Hilfe leistet. Er legt sich während der Exspiration eng an den Gaumen, ersetzt also die fehlenden Mundklappen [der Plattfische] und drückt zugleich wie der Stempel einer Druckpumpe das Wasser in die seitlichen Kiemenhöhlen. Es konnte nun auch für den Plattfisch eine ähnliche Rolle des Zungenhügels nachgewiesen werden, diese ist für ihn aber nicht so wichtig wie für den Dorsch.

8. Kurz zusammengefaßt lautet das Ergebnis, daß beide Fischtypen, der freie Schwimmer mit seiner normalen und unspezialisierten Atmungsapparatur, sowie der Bodenfisch mit seinem spezialisierten Atmungsapparat Mund- und Kiemenhöhle bei normaler Atmung gebrauchen, also Druck- und Saugpumpenarbeit gleichzeitig leisten. Für den Dorsch liegt aber das Hauptgewicht auf der Druckpumpenarbeit der Mundhöhle, für den Plattfisch dagegen auf der Saugpumpenarbeit der seitlichen Kiemenhöhlen. 


\section{Sehriftenverzeichnis.}

Babik, E.: Die Mechanik und Innervation der Atmung - Winterstein's Handb. d. vergl. Physiol. $1,1931$. Bicilioni, S.: Der Atemmechanismus der Fische - Zeitschr. f. allg. Physiol. 7, 1907.

BLDDENBROCK, W. $\therefore$ : Vergleichende l'hysiologie -2.1939.

Colf, J. F. and J. Johnstone: L. M. B. C. Memoirs Typical British Marine Plants and Animals. VIII. Pleuronectes - Liverp. mar. Biol. Comm. London 1901.

D.xi, L. VAN: On the Utilization of Oxygen and Regulation of Breathing in some Aquatic Animals (ironingen 1938 . J)issertat.

I)Eganelio, U.: Die peripherischen nervösen Apparate des Atemrhythmus bei Knochenfischen. Eine anatonische und experimentelle Untersuchung. - Pflügers Arch. 123, 1908.

Hexschel, J.: Der Atmungsmechanismus der Fische. - Journ. d. Cons. int. p. lexpl. d. l. mer. 14.1939.

Homarist, 0 .: Der Musculus protractor hyoidei (geniohyoideus ant.) und der Senkungsmechanismus des Unterkiefers bei den Knorhenfischen: zugleich ein Beitrag zur Kenntuis der Atembewegungen. Fysiogr. Sällsk. Handlingar Lund 21, 1910.

Kioler, T. : Untersuchungen über die Atmung der Teleosteer. - Pflügers Arch. 117,.1907.

LAINLR, M.: Die Physiologie der Fischatmung. - Leipzig 1938.

Lombroso, L.: Ueber einige besondere Regulationsvorginge der Atembewegungen bei Knochenfischen. Pfliugers Arch, 119. 1907 .

MEyer, Heloi. Die Atmung ron Uranoscopus scaber und ihre Abhangigkeit rom Sauerstoffdruck. - Zeitschr. vergl. Physiol. 22, 19:3).

Nommix, J. R.: A Sirstematic Monograph of the Flatfishes. (Heterosomata.) - London 1934.

OLTHof, H. J.: Die Kohlensäure als Atemreiz bei Wassertieren, insbesondere bei Sübwasserfischen. - Zeitschr. vergl. Physiol. 21, 1935).

Vetter, B.: Kiemen- und Kiefermuskulatur der Fische. - Jen. Zeitschr. f. Naturw. 12, 1878.

Wintbrstein, H.: Beiträge zur Kenntnis der Fischatmung. - Pflüger's Arch. 125, 190s.

Moskobonikofr, M. M.: Der Apparat der Kemenatmung bei den Fischen. (Ein Versuch der Synthese in der Morphologie.) - Zool. Jahrb. Anat. 55, 19:32.

Wundis. W.: Physiologie der Süßwasserfische. - Handb. d. Binnenfischerei Mitteleur. 2. B, 1936. 